\title{
A Superstructure-Based Framework for Simultaneous Process Synthesis, Heat Integration, and Utility Plant Design
}

\author{
Lingxun Kong, S. Murat Sen, Carlos A. Henao, James A. Dumesic, \\ Christos T. Maravelias \\ Department of Chemical and Biological Engineering \\ University of Wisconsin - Madison \\ Madison, WI, 53706, USA
}

\begin{abstract}
We propose a superstructure optimization framework for process synthesis with simultaneous heat integration and utility plant design. Processing units in the chemical plant can be modeled using rigorous unit models or surrogate models generated from experimental results or off-line calculations. The utility plant subsystem includes multiple steam types with variable temperature and pressure. For the heat integration subsystem, we consider variable heat loads of process streams as well as variable intervals for the utilities. To enhance the solution of the resulting mixed-integer nonlinear programming models, we develop (1) new methods for the calculation of steam properties, (2) algorithms for variable bound calculation, and (3) systematic methods for the generation of redundant constraints. The applicability of our framework is illustrated through a biofuel case study which includes a novel non-enzymatic hydrolysis technology and new separation technologies, both of which are modeled based on experimental results.
\end{abstract}

Keywords: Chemical process design; mixed-integer nonlinear programming; global optimization; biofuels.

\section{Introduction}

A superstructure refers to a process diagram that includes all potentially useful processing units and all relevant connections. Superstructure frameworks have been proposed for solving process synthesis problems (Barnicki \& Siirola, 2004; Siirola, 1995; Trespalacios \& Grossmann, 2014; Yeomans \& Grossmann, 1999). By solving the superstructure optimization model, all process alternatives embedded are evaluated, and the best alternative is selected along with the optimal operation conditions for each unit.

Superstructure-based approaches have the advantage of simultaneously considering complex interactions between all design decisions. To identify good designs however the development of a rich superstructure is necessary, and at the same time rigorous unit operation models have to be used to obtain accurate results. Therefore, the resulting formulations are large-scale non-convex mixed-integer nonlinear programming (MINLP) models. 


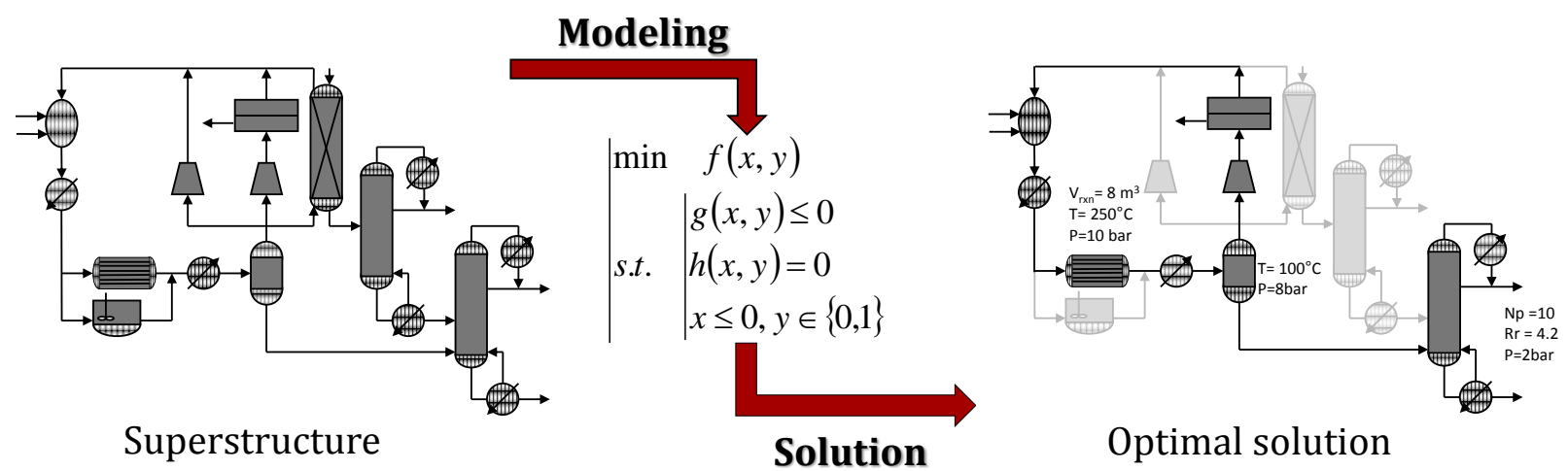

Figure 1. A superstructure representation in process synthesis problems.

In terms of superstructure generation, early works focused on the combination of simple structures formulated based on engineering judgment (Kocis \& Grossmann, 1989) and the combination of superstructure subsystems (e.g. reaction network, separation network, and heat recovery network) each created independently (Achenie \& Biegler, 1990; Floudas, Ciric, \& Grossmann, 1986; Floudas \& Paules, 1988; Hasan, Jayaraman, Karimi, \& Alfadala, 2010; Kokossis \& Floudas, 1994; Lakshmanan \& Biegler, 1996; Novak, Kravanja, \& Grossmann, 1996; Ponce-Ortega, Jimenez-Gutierrez, \& Grossmann, 2008; Schweiger \& Floudas, 1999; Yee \& Grossmann, 1990). Friedler et. al. later proposed a mathematical framework for the creation of superstructures and an algorithm to generate the so-call "maximal structure" (Friedler, Tarjan, Huang, \& Fan, 1992).

Once the superstructure is generated, all the units must be accurately modeled. In many cases, to ensure that the resulting superstructure model is computationally tractable, rigorous unit models are replaced by approximate models (e.g. shortcut methods). Aggarwal and Floudas proposed linear and bilinear approximations for the component split fractions in modeling separators (Aggarwal \& Floudas, 1990); Bausa et. al. incorporated the classic Underwood methods with other proposed techniques and developed a more general shortcut method called rectification body method (RBM), which is applicable to non-ideal multicomponent distillation with arbitrary splits (Bausa, Von Watzdorf, \& Marquardt, 1998); Yeomans and Grossman applied first principles models with simplified kinetics and thermodynamic properties to model tray-by-tray ideal distillation models (Yeomans \& Grossmann, 2000); Kraemer et. al. developed a shortcut-based design method for multicomponent heteroazeotropic distillation (Kraemer, Harwardt, Skiborowski, Mitra, \& Marquardt, 2011); Bruggemann and Marquardt proposed an optimization-based conceptual design framework for finding the optimal recycle policy for azeotropic distillation (Bruggemann \& Marquardt, 2011). However, the aforementioned methods address subsystems of a process.

Ideally, when solving process synthesis problems, we would like to integrate the design of the chemical plant with the design of the utility system and the heat recovery network. Papoulias and 
Grossman proposed a mixed-integer linear programming (MILP) formulation that integrates the three subsystems (Papoulias \& Grossmann, 1983b). Colmenares and Seider used a non-linear programming (NLP) model for integrating the design of the chemical plant with the utility plant (Colmenares \& Seider, 1989). More rigorous MINLP models were proposed later, including more accurate models for steam and gas turbines (Mavromatis \& Kokossis, 1998; Varbanov, Doyle, \& Smith, 2004; Wilkendorf, Espuna, \& Puigjaner, 1998); accurate steam property estimation (Aguilar, Perry, Kim, \& Smith, 2007; Bruno, Fernandez, Castells, \& Grossmann, 1998; Caballero, Navarro, Ruiz-Femenia, \& Grossmann, 2014; Rodriguez-Toral, Morton, \& Mitchell, 2001); and operational planning of utility systems (Francisco \& Matos, 2004; Iyer \& Grossmann, 1998). One limitation of the previous studies is the assumption that heating utilities have constant temperatures and pressures. A more realistic approach would be to allow steam temperatures and pressures to vary continuously and then accurately calculate steam thermodynamic properties (e.g. enthalpy) as a function of steam temperatures and pressures.

To address these challenges, we propose a superstructure framework that allows us to simultaneously perform (1) structural and parametric optimization for the chemical plant, (2) heat integration, and (3) utility plant design. To obtain realistic yet computationally tractable optimization models, we (1) employ unit surrogate models generated from experimental results or off-line simulations using rigorous models, (2) develop new expressions for the calculation of steam thermodynamic properties, (3) develop algorithms for the calculation of tight variable bounds, and (4) develop systematic ways for the generation of redundant constraints.

The paper is structured as follows. In section 2, we present the superstructure modeling framework consisting of three main subsystems: the chemical plant, the heat integration subsystem, and the utility plant along with a thermodynamic properties calculation module. In section 3 , we discuss the algorithms for the calculation of variable bounds and the generation of redundant constraints. Finally, in section 4, we illustrate the applicability of the proposed framework through the design of a lignocellulosic ethanol facility employing a novel non-enzymatic biomass hydrolysis technology.

\section{Superstructure Modeling Framework}

The conceptual integration of the chemical plant, heat integration, and utility plant subsystems is illustrated in Figure 2. We develop general modeling strategies for each subsystem, and identify the variables that connect them. While all subsystems are connected with each other, the modeling equations for each one of them are independent from each other; they are interfaced via some interconnecting variables (to be discussed later). Thus, the integrated model can be applied to a wide range of chemical production processes. 




Figure 2. Subsystems and their interactions.

\subsection{Chemical Plant}

To model the chemical plant superstructure, we introduce four basic sets: (1) processing units $i \in \mathbf{I}$, (2) streams $j \in \mathbf{J}$, (3) compounds $k \in \mathbf{K}$, and (4) reactions $r \in \mathbf{R}$. Subsets of compounds include raw materials $\mathbf{K}^{\mathbf{R}}$, products $\mathbf{K}^{\mathbf{P}}$, byproducts $\mathbf{K}^{\mathbf{B P}}$, and other materials $\mathbf{K}^{\mathbf{M}}$ such as solvents and intermediate products. Based on the processing functions, each type of unit has certain number of inlets and outlets. Streams are used to connect the inlet and outlet between two processing units or supply/remove materials to/from the plant. The main binary variables are the unit selection variables; non-negative continuous variables include material flows, unit operating conditions (temperature and pressure), heat duties, conversions (reactors), component recoveries (separation units), and equipment sizes and costs. In general, equality constraints arise from unit material and energy balances, design equations, correlation of experimental data, and equipment sizing, while inequality constraints come from design and product specifications.

\subsubsection{Unit Models}

For a processing unit, $i \in \mathbf{I}$ with arbitrary number of inlet $\left(j \in \mathbf{J}_{i}^{\mathbf{I N}}\right)$ and outlet streams $\left(j \in \mathbf{J}_{i}^{\text {OUT }}\right)$, a flow-based explicit formulation can be written as follows (see also Figure 3):

$$
\begin{aligned}
& F_{j^{\prime}, k}=f_{j^{\prime}, k}^{F}\left(\left[F_{j, k}, T_{j}\right]_{\substack{j \in \mathbf{J}_{i}^{\mathbf{I N}} \\
k \in \mathbf{K}}}, \psi_{i}\right) \quad j^{\prime} \in \mathbf{J}_{i}^{\mathbf{O U T}}, k \in \mathbf{K} \\
& T_{j^{\prime}}=f_{j^{\prime}}^{T}\left(\left[F_{j, k}, T_{j}\right]_{\substack{j \in \mathbf{J}_{i}^{\mathbf{I N}} \\
k \in \mathbf{K}}}, \psi_{i}\right) \quad j^{\prime} \in \mathbf{J}_{i}^{\text {OUT }} \\
& Q_{i, l}=f_{i, l}^{Q}\left(\left[F_{j, k}, T_{j}\right]_{\substack{j \in \mathbf{J}_{i}^{\mathrm{IN}}, k \in \mathbf{K}}} \psi_{i}\right) \quad l \in \mathbf{L}_{i}^{\mathbf{Q}} \\
& W_{i, l}=f_{i, l}^{W}\left(\left[F_{j, k}, T_{j}\right]_{\substack{j \in \mathbf{J}_{i}^{\mathbf{I N}} \\
k \in \mathbf{K}}}, \psi_{i}\right) \quad l \in \mathbf{L}_{i}^{\mathbf{W}}
\end{aligned}
$$




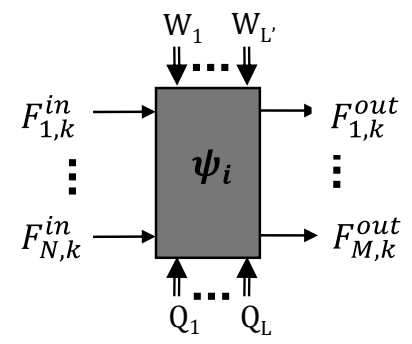

Figure 3. General processing unit.

$$
\begin{gathered}
C c_{i}=f^{C c}\left(\left[F_{j, k}, T_{j}\right]_{\substack{j \in \mathbf{J}_{i}^{\mathrm{IN}} \\
k \in \mathbf{K}}}, \psi_{i}\right) \\
C o_{i}=f^{C o}\left(\left[Q_{l, i}\right]_{l \in \mathbf{L}_{i}^{\mathrm{Q}}},\left[W_{l, i}\right]_{l \in \mathbf{L}_{i}^{\mathrm{W}}}\right)
\end{gathered}
$$

where equations (1) - (4) represent the nonlinear functions of the unit model relating the unit model degrees of freedom with the material flows and temperatures of all the outlet streams, as well as the utility requirements $\left(Q_{i, l}\right.$ and $\left.W_{i, l}\right)$. In eqns. (3) and (4), $\mathbf{L}_{i}^{\mathbf{Q}} / \mathbf{L}_{i}^{\mathbf{W}}$ represent the distinct heat loads/power requirements of a processing unit (e.g. condenser and reboiler heat loads in a distillation column). The unit model is fully specified if all the inlet stream state variables and unit internal variables $\psi_{i}$ are given. It is important to note here that while the representation of the unit model via eqns. (1) - (6) is the "natural" way to represent a unit model, an explicit form is not typically available. Nevertheless, the same variables can be used as independent variables to fully specify the system. Also, we note that variables $\psi_{i}$ are independent of the inlet stream conditions but depend on the unit types. For example, $\psi_{i}$ are the number of stages for a multi-stage extraction unit, while they are volume, temperature, and pressure for a reactor unit. Equations (5) and (6) are functions that estimate the unit capital and operational costs, respectively.

The flow-based formulation can be expressed in the following general form,

$$
\begin{gathered}
x_{3}=f\left(x_{1}, x_{2}\right) \\
\underline{x}_{1} \leq x_{1} \leq \bar{x}_{1} \\
\underline{x}_{2} \leq x_{2} \leq \bar{x}_{2}
\end{gathered}
$$

where $x_{1}$ are independent state variables of the inlet stream $\left(F_{j, k}\right.$ and $\left.T_{j}\right), x_{2}$ are independent unit internal variables $\left(\psi_{i}\right)$ for unit $i$, and $x_{3}$ are dependent variables including component flows and temperatures for all the outlet streams, utility consumptions, and costs. The first equation, $x_{3}=f\left(x_{1}, x_{2}\right)$, groups all nonlinear functions (eqns. (1) - (6)) that relate the dependent variables with independent variables. The second and third equations define the domains of the nonlinear equations.

The first-principles models provide an effective modeling way if they are relatively simple. However, in cases where unit models are either not available or too complex, surrogate models can 
be employed (Caballero \& Grossmann, 2008; Henao \& Maravelias, 2011; Shao, Krishnamurty, \& Wilmes, 2007; Won \& Ray, 2005). The use of surrogate instead of rigorous unit models reduces the modeling complexity while preserving reasonable level of accuracy. Surrogate models can be generated from data that comes from offline simulations or experiments.

For example, experimental results can be used to develop reactor surrogate models which are more realistic than fixed-conversion linear reactor models. We first conduct experiments to determine the correlations between the conversion of limiting component and independent variables such as temperature, pressure, and feed compositions. Then the conversion expression obtained from the nonlinear equations in eqn. (8) is included in the component material balances that relate the inlet and outlet component flows.

$$
C_{r}=f\left(\left[P_{j}, T_{j}, X_{j, k}\right]_{\substack{j \in \mathbf{J}_{i}^{\mathrm{IN}} \\ k \in \mathbf{K}}}, \ldots\right) \quad r \in \mathbf{R}
$$

Commercial process simulators (e.g ASPEN Plus) are also very powerful in generating reliable data for most unit operations with the help of the integrated detailed unit operation and thermodynamic models. We will use data generated from ASPEN Plus to develop surrogate model for the $\mathrm{CO}_{2}$ recovery system in our case study presented in Section 4.

\subsubsection{Superstructure Modeling}

In a superstructure framework involving the selection of process alternatives, the nonlinear equations $x_{3}=f\left(x_{1}, x_{2}\right)$ in eqn. (7) in general can be reformulated as $x_{3}=\bar{f}\left(x_{1}, x_{2}, y\right)$, where $y$ is a binary variable which is 1 if the unit is selected. This reformulation should satisfy $x_{3}=$ $\bar{f}\left(x_{1}, x_{2}, 1\right)=f\left(x_{1}, x_{2}\right)$, while it is desirable to also satisfy $\bar{f}(0,0,0)=0$ so that enforcing $\left(x_{1}, x_{2}\right)=0$ if $y=0$ is sufficient to deactivate the unit (i.e. enforce $\left.\left(x_{1}, x_{2}, x_{3}\right)=0\right)$. In other words, forcing the independent variable $\left(x_{1}, x_{2}\right)$ to zero guarantees the deactivation of the corresponding dependent variables $\left(x_{3}\right)$. If this property is satisfied, then the unit model in equation (7) can be reformulated as follows:

$$
\begin{gathered}
x_{3}=\bar{f}\left(x_{1}, x_{2}, y\right) \\
\underline{x}_{1} \cdot y \leq x_{1} \leq \bar{x}_{1} \cdot y \\
\underline{x}_{2} \cdot y \leq x_{2} \leq \bar{x}_{2} \cdot y
\end{gathered}
$$

The complete reformulation of the flow-based unit model in eqns. (1) - (6) is given in Appendix A. Note that in some cases (e.g. modeling of separation units) some of the constraints in eqn. (1) are linear component material balances and therefore some of $x_{3}=f\left(x_{1}, x_{2}\right)$ in eqn. (7) are homogeneous linear equations. In these cases, it is possible to enforce $\left(\left[x_{1}, x_{2}\right]=0\right) \rightarrow\left(\left[x_{1}, x_{2}, x_{3}\right]=0\right)$ without using the unit selection binary variable. 
Variable upper bound constraints, which arise from the selection of units, are enforced. For example,

$$
F_{j}^{T} \leq \bar{F}_{j}^{T} Y_{i}^{\text {unit }} \quad i \in \mathbf{I}, j \in \mathbf{J}_{i}^{\mathbf{I N}}
$$

where $\mathbf{J}_{i}^{\mathrm{IN}}$ is a set of all inlet streams of unit $i, F_{j}^{T}$ is the total molar flow, $\bar{F}_{j}^{T}$ is a valid upper bound on the total molar flow, and $Y_{i}^{\text {unit }}$ is the unit selection binary used to (de)activate a unit. In principle, constraints similar to eqn. (10) should be written for all the independent variables $\left(x_{1}, x_{2}\right)$ in the flow-based unit model.

Note that while $\left(x_{1}, x_{2}\right)=0$ in eqn. (9) is sufficient to ensure $x_{3}=0$, it is not necessary. Since a subset of $\left(x_{1}, x_{2}\right)$ are intensive variables (e.g. inlet stream temperatures and unit internal variables) which can take non-zero values when the unit is deactivated $\left(Y_{i}^{\text {unit }}=0\right)$, it is sufficient to ensure that every dependent variable becomes zero when the extensive inlet component flow rates are zero. Similarly, the subset of intensive $x_{3}$ variables do not need to be set to zero when $Y_{i}^{\text {unit }}=0$.

Furthermore, three types of logic constraints can be included in the superstructure when necessary. The first type enforces the selection of only one unit among all possible alternatives for a given task (e.g. three separation options for solvent recovery). A second type of equality constraints is used when some units must be selected or not selected simultaneously (e.g. two distillation columns in series). The third type is used to enforce logic relationship among "conditional units". For example, a reactor is followed by three separation alternatives, and the existence of the reactor is a prerequisite for selecting any of the separation systems. These logic constraints are discussed in detail elsewhere (Papoulias \& Grossmann, 1983b).

Finally, we introduce the concept of selection mixer ( $\mathrm{sm}$ ) and selection splitter (ss). These units are essential to model the unit connectivity and the selection of alternatives. As shown in Figure 4, the selection splitter is used to "direct" the inlet stream (stream 1) into only one of the two alternative units via stream 2 or 3 . A selection mixer combines the outlet streams (stream 4 and 5) from alternative units, of which only one will be active, into one stream (stream 6).

General material balances, as those written for a generic mixer $(\mathrm{gm})$ and splitter $(\mathrm{gs})$, are written,

$$
\begin{array}{ll}
F_{1, k}=F_{2, k}+F_{3, k} & k \in \mathbf{K} \\
F_{6, k}=F_{4, k}+F_{5, k} & k \in \mathbf{K}
\end{array}
$$




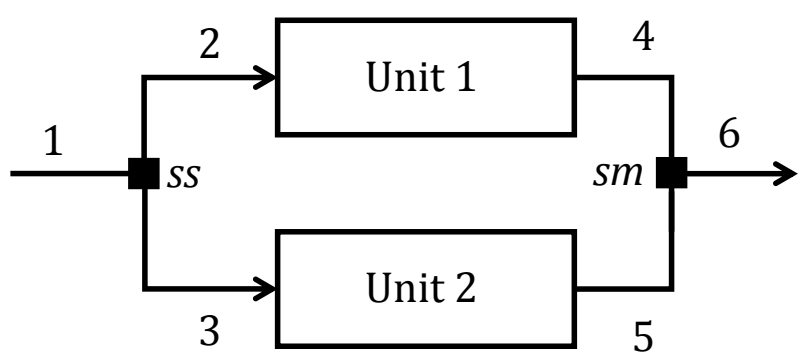

Figure 4. A simplified superstructure example. Unit 1 and unit 2 are process alternatives.

However, since only one of the alternative units can be selected in any feasible solution (Eq. (15)), either stream 2 or stream 3 will be activated, so no actual splitting is allowed in the selection splitter. Thus, the constraints that enforce composition equality among the selection splitter outlet streams are not necessary.

$$
\begin{gathered}
F_{2}^{T} \leq \bar{F}_{2}^{T} Y_{1}^{\text {unit }} \\
F_{3}^{T} \leq \bar{F}_{3}^{T} Y_{2}^{\text {unit }} \\
Y_{1}^{\text {unit }}+Y_{2}^{\text {unit }}=1
\end{gathered}
$$

\subsection{Heat Integration}

The heat integration subsystem allows heat integration among process streams to minimize utility consumption. We construct a heat cascade (Figure 5a) modeled as a transshipment problem (Papoulias \& Grossmann, 1983a), but with variable stream heat duties (determined by the chemical plant model) and variable steam temperatures (determined by the utility plant model). Temperature intervals $m \in \mathbf{M}$ are constructed from the highest to the lowest based on the temperatures of the process streams (assumed fixed). All the initial and final temperatures of the streams are shifted to account for the minimum approach temperature $\left(\Delta T^{\mathrm{min}}\right)$.

In the transshipment model, hot process streams $j \in \mathbf{J}^{\mathbf{H}}$ and hot utilities $j \in \mathbf{J}^{\mathbf{U S}}$ are treated as source nodes, while cold process streams $j \in \mathbf{J}^{\mathbf{C}}$ and cold utilities $j \in \mathbf{J}^{\mathbf{U N}}$ are considered sink nodes. Heat can be seen as a commodity to be transferred from the sources to the sinks via temperature intervals which correspond to some intermediate "warehouses". Residue heat $\left(Q R_{m}\right)$ from any temperature interval is cascaded down to the next interval at a lower temperature. Heat balance in each interval is given by,

$$
Q R_{m-1}+\sum_{j \in \mathbf{J}^{\mathbf{H}}} Q_{j, m}^{h}+\sum_{j \in \mathbf{J}^{\mathbf{U S}}} Q_{j, m}^{h}=Q R_{m}+\sum_{j \in \mathbf{J}^{\mathbf{C}}} Q_{j, m}^{c}+\sum_{j \in \mathbf{J}^{\mathbf{U N}}} Q_{j, m}^{c} m \in \mathbf{M}
$$

where $Q_{j, m}^{h}, j \in \mathbf{J}^{\mathbf{H}}$ and $Q_{j, m}^{h}, j \in \mathbf{J}^{\mathbf{U S}}$ are heat delivered to the temperature interval $m$ by hot process streams and hot utilities, while $Q_{j, m}^{c}, j \in \mathrm{J}^{\mathbf{C}}$ and $Q_{j, m}^{c}, j \in \mathbf{J}^{\mathrm{UN}}$ denote heat received by cold process streams and cold utilities, respectively. The heat integration ensures maximum heat exchange 
among process streams, while satisfying the second law of thermodynamics and $\Delta T^{m i n}$ as a heat exchanger design requirement.

Three types of steams (high, medium, and low) are produced in the utility plant. Unlike previous approaches, temperature and pressure for each type of steam are allowed to continuously vary. Each hot utility stream is assigned to a temperature interval via binary variables $\left(Y_{j, m}\right)$ based on their saturation temperatures $\left(T_{j}^{\text {sat }}\right)$ using eqns. (17) - (20),

$$
\begin{gathered}
\sum_{m} Y_{j, m} \leq 1 \quad j \in \mathbf{J}^{\mathbf{U S}} \\
Y_{j, m} \underline{T}_{m} \leq T_{j, m}^{h} \leq Y_{j, m} \bar{T}_{m} \quad j \in \mathbf{J}^{\mathbf{U S}}, m \in \mathbf{M} \\
\sum_{m} T_{j, m}^{h}+T_{j}^{d}=T_{j}^{s a t} \quad j \in \mathbf{J}^{\mathbf{U S}} \\
T_{j}^{d} \leq\left(1-\sum_{m} Y_{j, m}\right) \bar{T}_{j}^{\text {sat }} \quad j \in \mathbf{J}^{\mathbf{U S}}
\end{gathered}
$$

where $\underline{T}_{m}$ and $\bar{T}_{m}$ are lower and upper bounds on the temperature of interval $m$, and $\bar{T}_{j}^{\text {sat }}$ is a valid upper bound on the saturation temperature of each hot utility stream. Variable $T_{j, m}^{h}$ is a disaggregated temperature of the hot utility that only takes non-zero values when hot utility $j \in$ $\mathbf{J}^{\mathbf{U S}}$ is assigned to the temperature interval $m\left(Y_{j, m}=1\right) ; T_{j}^{d}$ is a dummy temperature that takes the value of $T_{j}^{\text {sat }}$ when hot utility $j \in \mathbf{J}^{\mathbf{U S}}$ is not assigned to any of the temperature interval. An example of these assignments is illustrated in Figure $5 \mathrm{~b}$.

The heat integration model is connected with the utility plant model via the heat delivered by each hot utility stream $Q_{j}^{h}, j \in \mathbf{J}^{\mathbf{U S}}$. Steam can deliver heat to the next lower temperature interval (eqn. (21)). Heat delivered to interval $m$ by hot utilities $Q_{j, m}^{h}, j \in \mathbf{J}^{\mathbf{U S}}$ and heat received from that interval by cold utilities $Q_{j, m}^{c}, j \in \mathrm{J}^{\mathrm{UN}}$ are calculated using equations (22) and (23), respectively,

$$
\begin{gathered}
Q_{j, m}^{h} \leq Y_{j, m+1} \bar{Q}_{j}^{h} \quad j \in \mathbf{J}^{\mathbf{U S}}, m \in \mathbf{M} \\
\sum_{m} Q_{j, m}^{h}=Q_{j}^{h} \quad j \in \mathbf{J}^{\mathbf{U S}} \\
Q_{j, m}^{c}=F_{j, m}^{i n t} C p_{j} \Delta T_{m} \quad j \in \mathbf{J}^{\mathbf{U N}}, m \in \mathbf{M}
\end{gathered}
$$

where $\bar{Q}_{j}^{h}$ is an upper bound on the heat delivered to the intervals, $F_{j}, j \in \mathbf{J}^{\mathbf{U S}}$ is the mass flow rate of hot utility stream, $F_{j, m}^{i n t}, j \in \mathrm{J}^{\mathrm{UN}}$ is the mass flow rate of cooling utility stream $j$ in each temperature interval $m, C p_{j}$ is the heat capacity of the utility stream, and $\Delta T_{m}$ represents the temperature difference in interval $m$. 
(a)

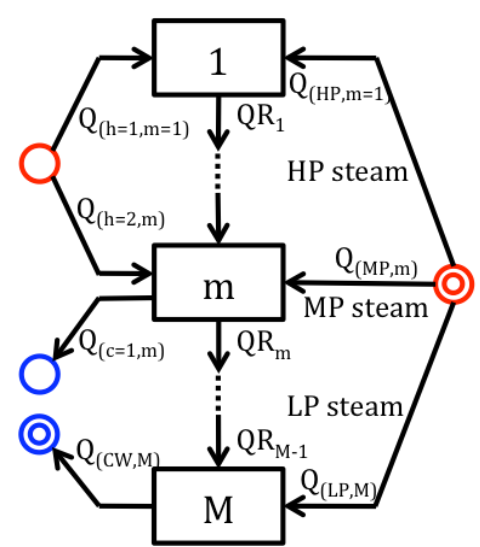

(b)

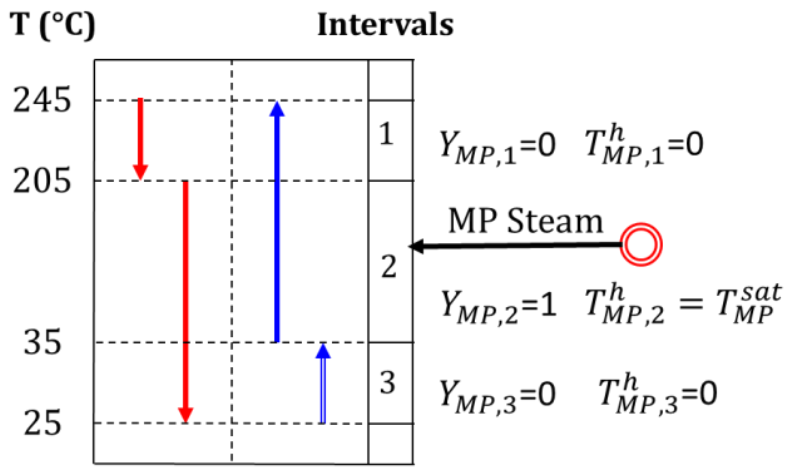

(2) Hot utility stream

() Cold utility stream

Hot process stream

Cold process stream

Figure 5. (a) Heat cascade diagram for heat integration, and (b) an example of variable-temperature MP steam assigned to the temperature intervals.

Heat duties of hot and cold streams are determined by the stream properties $\left(F_{j}, C p_{j}\right)$ in the chemical plant subsystem and expressed as follows,

$$
\begin{gathered}
Q_{j, m}^{h}=F_{j} C p_{j} \Delta T_{m} \quad j \in \mathbf{J}^{\mathbf{H}}, m \in \mathbf{M}_{j} \\
Q_{j, m}^{c}=F_{j} C p_{j} \Delta T_{m} \quad j \in \mathbf{J}^{\mathbf{C}}, m \in \mathbf{M}_{j}
\end{gathered}
$$

where $\mathbf{M}_{j}$ is a subset of all the temperature intervals that process stream $j$ spans. While eqns. (24) and (25) are written for process streams with no phase changes, the proposed approach can also handle streams with a simple isothermal phase change; e.g., evaporation of single component. Such streams are modeled to span only one temperature interval, and the corresponding heat duty $\left(Q_{j, m}^{c}\right)$ at that interval can be calculated by replacing the heat capacity $\left(C p_{j}\right)$ in eqn. (25) with latent heat $\left(\lambda_{j}^{e v p}\right)$ and setting $\Delta T_{m}=1$.

In principle, flow rates, heat capacities, temperatures, and heat loads of process streams can be defined as variables instead of parameters as in the original LP transshipment model (Papoulias \& Grossmann, 1983a). Here, we allow flow rates and heat loads of the process streams to vary but fix their temperatures and assume constant heat capacity to avoid nonlinearities in eqns. (24) and (25). This is a reasonable assumption if the operating temperatures of the processing units are fixed or allowed to vary within small ranges.

Since all steam types are generated in the utility plant subsystem, the only utility cost considered in this subsystem is the cost of cooling water. The amount of cooling water used $\left(F_{C W}^{c o o l}\right)$ is calculated by

$$
F_{C W}^{c o o l}=\sum_{m} \sum_{j \in \mathbf{J}^{\mathrm{UN}}} F_{j, m}^{i n t}
$$


The cost of cooling water for cold utility is combined with the cost of cooling water for condensation in the utility plant model, and the total cooling cost is included in the utility operating cost.

The linear transshipment model with variable flows and variable steam temperatures provides a simple yet effective way to account for heat integration that can be incorporated into a superstructure optimization framework with any chemical plant and utility plant subsystem by including equations (16) to (26). The heat integration can be extended by replacing the transshipment model with the expanded transshipment model (Papoulias \& Grossmann, 1983a) to match the cold and hot streams in each temperature interval. The transshipment model can also be extended to the MILP transshipment model (Papoulias \& Grossmann, 1983a) to account for the trade-off between energy and number of heat exchangers.

\subsection{Utility Plant}

As shown in Figure 6, the utility plant subsystem produces high-pressure (HP) steam through a boiler that combusts either fuel (e.g. natural gas) that is purchased or streams provided by the chemical plant subsystem. HP steam can be expanded to medium pressure (MP) or low pressure (LP) steam through let-down valves or turbines. Note that each type of steam, denoted in this subsystem by $u \in \mathbf{U}^{\mathbf{S}}$, becomes a hot utility in the heat integration subsystem, represented $j \in \mathbf{J}^{\mathbf{U S}}$. In other words, there is one-to-one correspondence between $u \in \mathbf{U}^{\mathbf{S}}$ in the utility plant subsystem and $j \in \mathbf{J}^{\mathbf{U S}}$ in the heat integration subsystem. Further, since steam (i.e. water) is the only component in any utility stream in the heat integration and utility plant, the properties of a stream are equivalent to the properties of the steam within that stream (e.g. $T_{j \in \mathrm{J}^{\mathrm{US}}}=T_{u \in \mathbf{U}^{\mathrm{s}}}$ ).

Utility demands are variables determined through the heat integration subsystem. Other optimization decisions include the types of units installed, the amount of electricity produced and/or purchased, the amount of steam (HP, MP, and LP) generated, and the steam conditions (temperature and pressure).

The utility plant is connected with the chemical plant through the flow of components used as fuels $\left(F_{f u e l, k}\right)$ with a given lower heating value (LHV), defined as the amount of heat released by combusting a specific quantity of fuel with an initial fuel temperature of $25^{\circ} \mathrm{C}$ and a final combustion product temperature of $150^{\circ} \mathrm{C}$. The heat generated in the boiler is given by,

$$
Q_{\text {boiler }}=\eta_{\text {boiler }} \sum_{k \in \mathbf{K}^{\mathbf{F}}} F_{\text {fuel, }, k} L H V_{k}
$$


where $\eta_{\text {boiler }}$ is the boiler efficiency. The amount of HP steam produced in the boiler $\left(F_{H P B}\right)$ can be determined from the heat generated in the boiler and steam enthalpy difference between boiler inlet and outlet,

$$
Q_{\text {boiler }}=F_{H P B}\left[H\left(T_{H P}, P_{H P}\right)-H\left(T_{b i n}, P_{H P}\right)\right]
$$

where $H\left(T_{b i n}, P_{H P}\right)$ is the enthalpy of subcooled liquid at the boiler inlet and $H\left(T_{H P}, P_{H P}\right)$ is the enthalpy of superheated HP steam at the boiler outlet. They are calculated from the approximations of fitted thermodynamic data (calculations presented in Section 2.4).

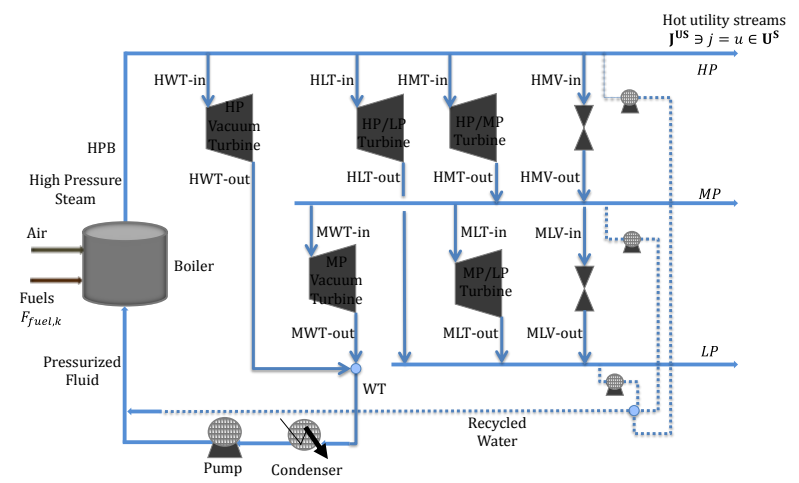

Figure 6. Utility plant subsystem.

HP steam can be used for heating, expanded to MP, LP, and/or wet (WT) steam via turbines, and/or converted to MP steam through a let-down valve as expressed in the following equation.

$$
F_{H P B}=F_{H P}+F_{H M T-i n}+F_{H L T-i n}+F_{H W T-i n}+F_{H M V-i n}
$$

Similarly, MP steam (produced from the HP steam) can be used for heating, expanded to LP and/or WT steam through turbines, and/or converted to LP steam through a valve (eqn. (30)), whereas LP steam, produced either from HP or MP steam, can only be used for heating in the process (eqn. (31)).

$$
\begin{gathered}
F_{H M T-i n}+F_{H M V-i n}=F_{M P}+F_{M L T-i n}+F_{M L V-i n}+F_{M W T-i n} \\
F_{H L T-i n}+F_{M L T-i n}+F_{M L V-i n}=F_{L P} \\
F_{W T}=F_{H W T-i n}+F_{M W T-i n}
\end{gathered}
$$

Note that for any turbine or valve, the steam mass flow rates are the same at the unit inlet and outlet (e.g. $F_{H M T-\text { in }}=F_{H M T-o u t}$ ). It is assumed that steam in each turbine undergoes isentropic expansion (from $u$ to $u^{\prime}$ ), so pressures and temperatures satisfy eqn. (33),

$$
\left(T_{u^{\prime}} / T_{u}\right)=\left(P_{u^{\prime}} / P_{u}\right)^{\gamma} u_{u, u^{\prime}} \quad\left(u, u^{\prime}\right) \in \boldsymbol{\Psi}
$$

where $\boldsymbol{\Psi} \in \mathbf{U}^{S} \times \mathbf{U}^{S}$ are the pairs of all the feasible combination of steams $u$ and $u^{\prime}$, and $\gamma_{u, u^{\prime}}$ is the expansion coefficient calculated from the average heat capacities $\left(C p_{u}^{v a p}\right)$ of the turbine inlet and outlet streams. The above relation holds true if the turbine is installed. To account for the selection 
of turbines, we reformulate eqn. (33) by introducing a pair of positive variables $\delta_{u, u^{\prime}}^{+}$and $\delta_{u, u^{\prime}}^{-}$, which will both be forced to zero via variable upper bound constraints if the turbine is selected. If the turbine is not selected, the right-hand-side of eqn. (34) can take nonzero values to avoid infeasibilities.

$$
T_{u^{\prime}}\left(P_{u}\right)^{\gamma} u, u^{\prime}-T_{u}\left(P_{u^{\prime}}\right)^{\gamma} u, u^{\prime}=\delta_{u, u^{\prime}}^{+}-\delta_{u, u^{\prime}}^{-} \quad\left(u, u^{\prime}\right) \in \boldsymbol{\Psi}
$$

For vacuum turbines, the isentropic expansion expression is modified with a term to account for the entropy of condensation $\left(\Delta S^{\text {cond }}\right.$ ) of the wet steam with liquid fraction $(\varphi)$ of $10 \% . \Delta S^{\text {cond }}$ is assumed to be a constant at $7.5 \mathrm{~kJ} / \mathrm{kg} \cdot \mathrm{K}$ at the pressure range of $0.02-0.5 \mathrm{bar}$, which corresponds to a saturation temperature range of 290-350 K.

$$
C p_{u}^{v a p} \ln \left(\frac{T_{u^{\prime}}}{T_{u}}\right)-R^{\text {univ }} \ln \left(\frac{P_{u^{\prime}}}{P_{u}}\right)-\varphi \Delta S^{\text {cond }}=\delta_{u, u^{\prime}}^{+}-\delta_{u, u^{\prime}}^{-} \quad u \in \mathbf{U}^{\mathbf{S}}, u^{\prime}=\{\mathrm{WT}\}
$$

As mentioned previously, steam at a higher pressure level can be expanded through a let-down valve to a lower pressure level. In such operations, changes in kinetic energy are negligible when the cross-sectional area for flow in the feed and effluent lines have been chosen to make the fluid velocity the same at the inlet and the outlet. Assuming that changes in kinetic and potential energy are negligible and the throttling device is adiabatic, then the throttling device is isenthalpic and the following equation holds true,

$$
Z_{u} T_{u}=Z_{u^{\prime}} T_{u^{\prime}} \quad\left(u, u^{\prime}\right) \in \boldsymbol{\Psi}
$$

where $Z_{u}$ is the compressibility factor of steam $u$. Similar to the modeling of turbines, positive slack variables $\epsilon_{u, u^{\prime}}^{+}$and $\epsilon_{u, u^{\prime}}^{-}$are introduced along with the binaries and big-M constraints to force both $\epsilon_{u, u^{\prime}}^{+}$and $\epsilon_{u, u^{\prime}}^{-}$to be zero if the valve is selected. Eqn. (37) is the reformulated isenthalpic expansion equation for let-down valves.

$$
Z_{u} T_{u}-Z_{u^{\prime}} T_{u^{\prime}}=\epsilon_{u, u^{\prime}}^{+}-\epsilon_{u, u^{\prime}}^{-} \quad\left(u, u^{\prime}\right) \in \boldsymbol{\Psi}
$$

The total electricity generated in turbines $\left(W^{\text {turbine }}\right)$ is calculated as a function of the steam flow rate, enthalpy difference and the turbine efficiency $\left(\eta_{i}\right)$.

$$
W^{\text {turbine }}=\sum_{i \in \mathbf{I}^{\mathbf{T}}} \eta_{i} F_{j}\left(H_{j}-H_{j^{\prime}}\right) \quad j \in \mathbf{J}_{i}^{\mathbf{I N}}, j^{\prime} \in \mathbf{J}_{i}^{\text {OUT }}
$$

The heat available in each hot utility stream $\left(Q_{j}^{h}, j \in \mathbf{J}^{\mathbf{U S}}\right)$ is used to provide heat to the cold process streams and connects the utility plant to the heat integration subsystem:

$$
Q_{j}^{h}=F_{j}\left(H_{j}-H_{j}^{\text {sat,liq }}\right) \quad j \in \mathbf{J}^{\mathbf{U S}}
$$

Prior to recycling back to the boiler, saturated condensates are pressurized to the corresponding HP steam pressure $\left(P_{H P}\right)$. The total work done by the pumps $\left(W^{\text {pump }}\right)$ can be calculated as follows: 


$$
W^{\text {pump }}=\sum_{j \in \mathbf{J}} \frac{F_{j}\left(P_{H P}-P_{j}\right)}{\eta_{p u m p} \rho_{j}}+\frac{F_{W T}\left(P_{H P}-P_{W T}\right)}{\eta_{p u m p} \rho_{W T}}
$$

where $\eta_{\text {pump }}$ is the pump efficiency, and stream $j \in \mathbf{J}^{\text {COND }}$ represents the condensate for each type of steam.

The electricity demand for the chemical plant and the pumps in the utility plant are satisfied by the electricity generated from the turbines and electricity purchased from the grid (if necessary). A binary variable $\left(Y^{\text {sale }}\right)$ is used to ensure electricity purchase (sale) takes place only when there is an electricity shortage (surplus), respectively,

$$
\begin{gathered}
W^{\text {sale }}-W^{\text {purchase }}=W^{\text {turbine }}-\left(W^{\text {demand }}+W^{\text {pump }}\right) \\
W^{\text {sale }} \leq Y^{\text {sale }} \bar{W}^{\text {sale }} \\
W^{\text {purchase }} \leq\left(1-Y^{\text {sale }}\right) \bar{W}^{\text {purchase }}
\end{gathered}
$$

where $\bar{W}^{\text {sale }}$ and $\bar{W}^{\text {purchase }}$ are valid upper bounds.

The cooling requirement ( $Q^{\text {cond }}$ ) for the condensation of wet steam at the vacuum turbine effluent is calculated by eqn. (44), where enthalpy of condensation $\left(h^{\text {cond }}\right)$ is averaged over a range of temperature and pressure, and the liquid fraction of the wet steam effluent $(\varphi)$ is assumed to be $10 \%$.

$$
Q^{\text {cond }}=(1-\varphi) F_{W T} h^{\text {cond }}
$$

Then, the amount of cooling water required for condensation is calculated from $Q^{\text {cond }}$,

$$
Q^{\text {cond }}=F_{C W}^{c o n d} C p_{C W}^{\text {liq }} \Delta T_{C W}
$$

Combining the cooling water for wet steam condensation $\left(F_{C W}^{c o n d}\right)$ with that for cooling process streams $\left(F_{C W}^{c o o l}\right)$ calculated from the heat integration, the total cooling water required $\left(F_{C W}^{\text {purchase }}\right)$ is determined.

$$
F_{C W}^{\text {purchase }}=F_{C W}^{\text {cond }}+F_{C W}^{\text {cool }}
$$

The utility plant capital cost consists of boiler cost, turbine cost, and pump cost, calculated from power law expressions. The utility plant operating cost comes from purchasing utilities (cooling water and electricity) and fuel. They will be combined with those from the chemical plant to determine the total annualized capital and utility cost that appear in the objective function.

\subsection{Steam Properties}

The specific heat capacity $C p(T)$ and specific enthalpy $H(T)$ of saturated liquid can be expressed in terms of temperature using the Shomate equation: 


$$
\begin{gathered}
C p(T)=a^{c p}+b^{c p} T+c^{c p} T^{2}+d^{c p} T^{3}+\frac{e^{c p}}{T^{2}} \\
H(T)=\left(a^{c p} T+\frac{b^{c p} T^{2}}{2}+\frac{c^{c p} T^{3}}{3}+\frac{d^{c p} T^{4}}{4}-\frac{e^{c p}}{T}+f^{c p}-h^{c p}\right)+h^{r e f}
\end{gathered}
$$

where $a^{c p}, b^{c p}, c^{c p}, d^{c p}, e^{c p}, f^{c p}$, and $h^{c p}$ are known constants, and $h^{r e f}$ is the enthalpy of the saturated liquid at the reference temperature of $298 \mathrm{~K}$. The specific heat capacity of the saturated condensate for each type of steam $\left(C p_{j}, j \in \mathbf{J}^{\text {COND }}\right)$ is calculated from a linear approximation of eqn. (47) based on the steam saturation temperature $\left(T_{j}^{s a t}\right)$. The enthalpy of the subcooled liquid at the boiler inlet, $H\left(T_{\text {bin }}\right)$, is approximated from the boiler inlet temperature $\left(T_{\text {bin }}\right)$ based on the linear approximation of eqn. (48). The average error for each approximation is less than $0.02 \%$. The results of both approximations are shown in Appendix C.

The boiler inlet temperature $\left(T_{b i n}\right)$ can be calculated from the following equation,

$$
T_{b i n} \sum_{u \in \mathbf{U}^{\mathrm{s}}} F_{j}=\sum_{u \in \mathbf{U}^{\mathrm{s}}} F_{j} T_{j} \quad j \in \mathbf{J}^{\text {PUMP }}
$$

where $T_{j}, j \in \mathbf{J}^{\mathbf{P U M P}}$ is the exit temperature of the pump determined as follows:

$$
T_{j}-T_{j}^{\text {sat }}=\left(\frac{1-\eta_{\text {pump }}}{\eta_{\text {pump }}}\right)\left(\frac{P_{H P}-P_{j}}{\rho_{j} C p_{j}}\right) \quad u \in \mathbf{U}^{\mathbf{S}}, j \in \mathbf{J}^{\text {PUMP }}
$$

The saturation temperature $\left(T_{u}^{s a t}\right)$ can be determined using the following Antoine equation at a given steam pressure $\left(P_{u}\right)$,

$$
T_{u}^{s a t}=\frac{a^{a n t}}{b^{a n t}+\ln \left(P_{u}\right)}-c^{a n t} \quad u \in \mathbf{U}^{\mathbf{S}}
$$

where $a^{\text {ant }}, b^{\text {ant }}$ and $c^{\text {ant }}$ are constants. To reduce the mathematical complexity, linear approximations of the above correlation (see Figure 7) are used for steams at different pressure ranges,

$$
T_{u}^{\text {sat }}=\bar{a}^{a n t} P_{u}+\bar{b}^{a n t} \quad u \in \mathbf{U}^{\mathbf{S}}
$$

where $\bar{a}^{a n t}$ and $\bar{b}^{\text {ant }}$ are constants for the linear approximations. The error of the approximated saturation temperature at a given pressure is less than $1 \%$.

The enthalpy of saturated liquid, $H\left(T_{u}^{\text {sat }}\right)$, can be calculated using a linear approximation of the Shomate equation at a range of temperature as shown in the following equation,

$$
H\left(T_{u}^{\text {sat }}\right)=a_{u}^{H s a t} T_{u}^{s a t}+b_{u}^{H s a t} \quad u \in \mathbf{U}^{\mathbf{S}}
$$

where $a_{u}^{\text {Hsat }}$ and $b_{u}^{\text {Hsat }}$ are constants for the linear approximation.

For each type of steam $u \in \mathbf{U}^{\mathbf{S}}$, the superheated steam enthalpy, $H\left(T_{u}, P_{u}\right)$, is estimated using the following equation,

$$
H\left(T_{u}, P_{u}\right)=a^{H}+b^{H} Z_{u} R^{u n i v} T_{u} \quad u \in \mathbf{U}^{\mathbf{S}}
$$


where $a^{H}$ and $b^{H}$ are constants, and $R^{\text {univ }}$ is the universal gas constant. The correlation is valid over a wide range of temperatures $\left(125-500^{\circ} \mathrm{C}\right)$ and pressures $(1-90 \mathrm{bar})$, with an average error of $0.08 \%$. To account for the non-ideal behavior of the vapor phase, vapor compressibility factor $\left(Z_{u}\right)$ can be calculated from the Redlich-Kwong (RK) equation of state (Redlich \& Kwong, 1949),

$$
Z_{u}^{3}-Z_{u}^{2}+Z_{u}\left(A-B-B^{2}\right)-A B=0
$$

where

$$
\begin{array}{r}
A=0.42747\left(\frac{P_{u}^{r e d}}{T_{u}^{r e d} \frac{5}{2}}\right) \\
B=0.08664\left(\frac{P_{u}^{r e d}}{T_{u}^{r e d}}\right)
\end{array}
$$

Variables $P_{u}^{\text {red }}$ and $T_{u}^{\text {red }}$ are the reduced pressure and temperature of steam, respectively. However, solving the compressibility factors using the above nonlinear RK equation of state is computationally difficult. Therefore, we derive a new equation for the given temperature and pressure ranges. The compressibility factor is first correlated with temperature at different pressure levels as a linear function, and the temperature dependence is introduced using the following expression:

$$
Z_{u}\left(T_{u}, P_{u}\right)=\hat{a}_{u}^{c m p} T_{u}+\hat{b}_{u}^{c m p} \quad u \in \mathbf{U}^{\mathbf{S}}
$$

where constants $\hat{a}_{u}^{c m p}$ and $\hat{b}_{u}^{c m p}$ are independent of temperature but dependent on the pressure $\left(P_{u}\right)$. By calculating $\hat{a}_{u}^{c m p}$ and $\hat{b}_{u}^{c m p}$ at different pressure levels, correlations between these constants and steam pressures are determined,

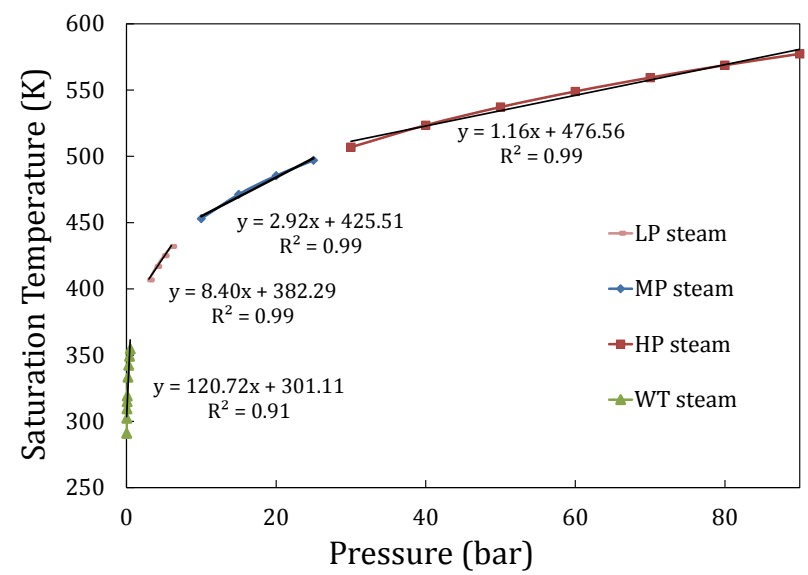

Figure 7. Linear approximation of Antoine equation to estimate saturation temperature. 


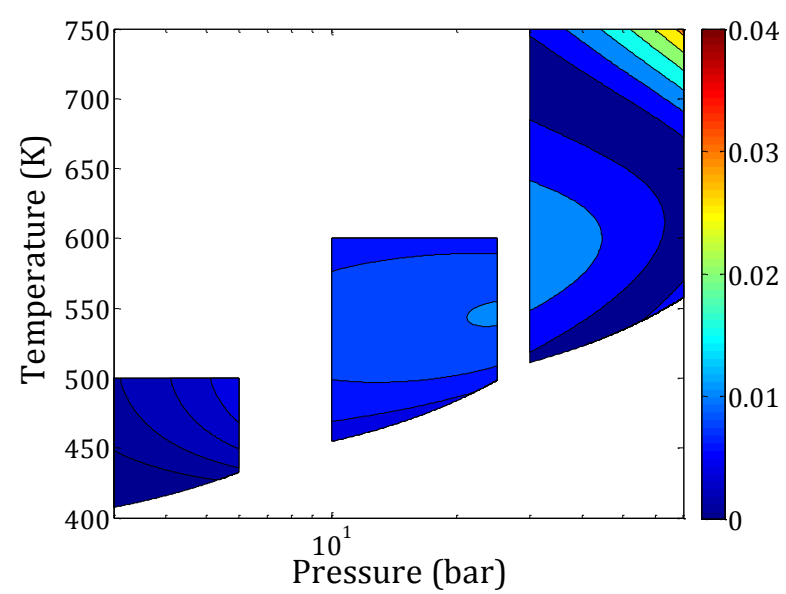

Figure 8. Relative errors in compressibility factors introduced by the approximation in eqn. (59). The pressure axis is plotted in logarithmic scale.

$$
\begin{gathered}
\hat{a}_{u}^{c m p}\left(P_{u}\right)=\hat{c}_{u}^{c m p} P_{u} \quad u \in \mathbf{U}^{\mathbf{S}} \\
\hat{b}_{u}^{c m p}\left(P_{u}\right)=\hat{c}_{u}^{c m p} P_{u}+\hat{d}_{u}^{c m p} \quad u \in \mathbf{U}^{\mathbf{S}}
\end{gathered}
$$

where $\hat{c}_{u}^{c m p}$ and $\hat{d}_{u}^{c m p}$ are coefficients of the linear approximation. Combining eqns. (56) - (58), we obtain an alternative equation for the calculation of the compressibility factor,

$$
Z_{u}=a_{u}^{c m p} P_{u} T_{u}+b_{u}^{c m p} P_{u}+c_{u}^{c m p} \quad u \in \mathbf{U}^{\mathbf{S}}
$$

where $a_{u}^{c m p}, b_{u}^{c m p}$ and $c_{u}^{c m p}$ are constants. The deviations of compressibility factor between eqn. (59) and eqn. (55) are calculated and plotted in Figure 8. The maximum deviation for LP, MP, and HP steam is $0.5 \%, 1.1 \%$, and $4.7 \%$, respectively.

\subsection{Integrated Model}

The proposed framework integrates the design of the chemical plant with the design of the utility plant and simultaneous heat integration. Given the process streams from the chemical plant, heat integration can be used to enable heat transfer among these streams and minimize utility consumptions. Heat load and flow rate of each process stream are variables that link the chemical plant and heat integration subsystems. The heat integration is linked to the utility plant by the heat available for each type of steam in the hot utility stream $\left(Q_{j}^{h}\right)$. The electricity demand ( $W^{\text {demand }}$ ) can be satisfied by the electricity generated in the utility plant. The amount of fuel $\left(F_{f u e l, k}\right)$ supplied by the process streams in the chemical plant to the boiler in the utility plant links the two subsystems. Using the integrated MINLP model, we are able to perform simultaneous parametric and structural optimization of the entire processing system. The variables connecting the three subsystems are shown in Figure 9. 




Figure 9. Integrated sub-systems and connecting variables.

\section{Solution Methods}

The proposed framework leads to the formulation of a nonconvex MINLP model, which means that we should use global optimization solvers to find the globally optimal solution. Recent developments on commercial global solvers enable us to solve medium-scale MINLP models within a reasonable amount of time (Achterberg, 2009; Misener \& Floudas, 2014; Sahinidis, 2014; Tawarmalani \& Sahinidis, 2011; Tawarmalani \& Sahinidis, 2005; Zorn \& Sahinidis, 2014). Nevertheless, even with the help of simplifications such as surrogate models and linear approximations, the MINLP models we are interested in solving are still computationally expensive. Therefore, additional efforts must be made to reduce the computational cost.

\subsection{Bound Generation}

The generation of tight variable lower and upper bounds can result in tighter convex relaxations of nonconvex constraints, which can in turn potentially improve the solution of MINLP models using global optimization solvers (Sahinidis, 2014; Tawarmalani \& Sahinidis, 2011). Accordingly, we develop an algorithm for the calculation of lower and upper bounds on component molar flows. Starting from bounds in the feed streams, which are usually provided as design specifications, bounds on component molar flows are propagated moving downstream. For example, using the upper bounds on the molar flows of reactants in the inlet stream of a reactor, we are able to calculate the upper bounds on products in the outlet stream using the maximum yield determined by reactor models or experiments. In the presence of recycle streams, a tearing idea is adopted in the bound propagations ((Velez, Sundaramoorthy, \& Maravelias, 2013); (Merchan, Velez, \& Maravelias, 2013)).

In any feasible solution, there will only be one inlet stream in a selection mixer ( $\mathrm{sm}$ ) and one outlet stream in a selection splitter (ss). Therefore, the upper bounds on component flows of ss outlet 
streams are the same as the upper bonds on the inlet stream, while the corresponding lower bounds will be zero. This can be illustrated by the following equations from the example in Figure 4 .

$$
\begin{gathered}
\bar{F}_{2, k}=\bar{F}_{3, k}=\bar{F}_{1, k} \quad k \in \mathbf{K} \\
\underline{F}_{2, k}=\underline{F}_{3, k}=0 \quad k \in \mathbf{K}
\end{gathered}
$$

For an $s m$, the upper bounds on outlet stream component flows are the maximum of the upper bounds among all the inlet streams (eqn. (62)).

$$
\bar{F}_{6, k}=\max \left(\bar{F}_{4, k}, \bar{F}_{5, k}\right) \quad k \in \mathbf{K}
$$

The lower bounds for a sm outlet streams can be calculated as the minimum among all the lower bounds on the flows of the inlets. However, the lower bounds calculated in this way might not be tight. In the superstructure example in Figure 4, suppose we are given a non-zero lower bound on component flow in stream 1. Following the bound propagation rules described above, the lower bounds on component flow for both stream 2 and 3 will be zero as shown in eqn. (61). After propagation, streams $2,3,4,5$, and 6 will therefore all have zero lower bounds on component flows. However, some components $k \in \mathbf{K}^{\mathbf{N}}$ may not be completely consumed in neither alternative (e.g., products recycled back to a reactor). Therefore, the lower bounds on the molar flow of component $k \in \mathbf{K}^{\mathbf{N}}$ in stream 6 can be non-zero. To address this, we calculate the lower bounds on stream 6 using a modified propagation method. If we are given the minimum recovery of component $k$ in each alternative $\left(\Omega_{1, k}\right.$ and $\left.\Omega_{2, k}\right)$ from the reactions and/or separations, then the lower bound on component flow in stream $6\left(F_{6, k}\right)$ can be expressed as follows:

$$
\underline{F}_{6, k}=\underline{F}_{1, k} \min \left(\Omega_{1, k}, \Omega_{2, k}\right) \quad k \in \mathbf{K}^{\mathbf{N}}
$$

where $\underline{F}_{1, k}$ is the lower bound on component molar flows in stream 1 . This results in a tighter (nonzero) lower bound on molar flow in stream 6 compared to that from bound propagation algorithm (provided none of $\underline{F}_{1, k}, \Omega_{1, k}$ or $\Omega_{2, k}$ equals zero for $k \in \mathbf{K}^{\mathbf{N}}$ ). This idea can be generalized and applied to any superstructure whenever a pair of $s s$ and $s m$ form a closed "subsystem".

Finally, some variables for the chemical plant processing units (e.g. sizes, costs, utility consumptions) are functions of component molar flows. Thereby bounds can also be generated on these variables using the bound propagation method. It is also possible to calculate bounds on variables in the heat integration and utility plant based on bounds on variables that link the subsystems (e.g. heat loads for the processing units, and electricity demand). The ideas outlined in this section will be illustrated using specific examples in Section 4. 


\subsection{Redundant Constraints}

To further reduce the search space, we systematically generate redundant constraints. We introduce inequality constraints on component molar flows around selection mixer and splitter. Based on Figure 4, an example of these constraints is shown below,

$$
\begin{gathered}
F_{2, k}+F_{3, k} \leq \bar{F}_{1, k} \quad k \in \mathbf{K} \\
F_{2, k}+F_{3, k} \geq \underline{F}_{1, k} \quad k \in \mathbf{K}
\end{gathered}
$$

where $\bar{F}_{1, k}$ and $\underline{F}_{1, k}$ are upper and lower bounds on component molar flow in stream 1 , respectively. Similar constraints can be written for $s m$ to relate the flow rates in stream 4, 5, and 6 .

Another group of redundant constraints are inequality constraints for the minimum flow rate of some streams if they are activated. In the example in Figure 4, we previously mentioned that all lower bounds on flows of stream 2, 3, 4, and 5 are zero. However, with a non-zero lower bound on flow in stream 1 , we can calculate the minimum component molar flow $\left(\hat{F}_{j, k}\right)$ for all down streams, if selected, meaning all the units associated with that stream are selected. These minimum flow rates are parameters which can be propagated moving downstream in a similar way. Finally, inequality constraints can be written for all streams connect to the superstructure alternatives:

$$
F_{j, k} \geq \widehat{F}_{j, k} Y_{i}^{\text {unit }} \quad i \in \mathbf{I}, j \in \mathbf{J}_{i}, k \in \mathbf{K}
$$

where $\mathbf{J}_{i}$ is a set of all streams connect to unit $i$. Similar inequality constraints can be written on other variables such as volume and capital cost of units using the corresponding minimum values and unit selection binaries.

These redundant constraints do not modify the feasible region, yet they can potentially contribute to constraint propagation methods, thus, enhancing the solution process.

\section{Case Study: Non-enzymatic Production of Ethanol from Biomass}

To illustrate the applicability of the proposed framework, we study the production of ethanol from lignocellulosic biomass via a non-enzymatic sugar production technology proposed recently. (Luterbacher et al., 2014)

\subsection{Technology Review}

Lignocellulosic biomass provides an alternative to conventional petroleum sources for satisfying the increasing global demand of fuels and chemicals (Naik, Goud, Rout, \& Dalai, 2010); (Kim, Sen, \& Maravelias, 2013). Recently, Luterbacher et. al. proposed a new lignocellulosic biomass-to-ethanol production strategy, in which cellulose and hemicellulose are simultaneously converted to sugars using biomass-derived $\gamma$-valerolactone (GVL) as a solvent and dilute acid as a catalyst (Luterbacher et al., 2014). The proposed strategy eliminates the costly biomass pretreatment steps which 
account for $25-30 \%$ of the total installed equipment cost (Han, Luterbacher, Alonso, Dumesic, \& Maravelias, 2015), and it avoids using expensive cellulase enzymes (Conde-Mejia, JimenezGutierrez, \& El-Halwagi, 2013; Kazi et al., 2010) in the sugar extraction steps.

In the proposed process, $\mathrm{C}_{5^{-}}$and $\mathrm{C}_{6}$-sugars (primarily xylose and glucose, respectively) are first produced in a biomass deconstruction system at 430-490 K using dilute sulfuric acid catalyst in GVL/water (4:1 wt\%) solution with a maximum biomass loading of $7 \mathrm{wt} \%$, and the remaining hemicellulose and cellulose are degraded to form humins. This reaction system leads to $100 \%$ conversion of hemicellulose and cellulose with a 70 mol\% yield of $\mathrm{C}_{6}$-sugars and $70-86$ mol\% yield of $\mathrm{C}_{5}$-sugars, depending on the GVL-to-biomass ratio. The high yield of sugars is a result of the complete solubilization of biomass solids in the presence of GVL that minimizes further degradation of the resulting $\mathrm{C}_{5}$ - and $\mathrm{C}_{6}$-sugars to insoluble products such as furfural, levulinic acid, and humins (Luterbacher et al., 2014). Note that the sugar yields are shown to be insensitive to biomass type, allowing us to evaluate different types of biomass feedstock without altering the reaction parameters (Luterbacher et al., 2014).

Although the proposed strategy leads to a high sugar yield and eliminates costly pretreatment steps, major challenges towards its commercialization are obtaining fermentable sugars at high purity and the effective separation of GVL from lignin and biomass residues. Thus, to produce fermentable sugars at low cost, a series of cost-effective separation technologies should be developed, evaluated, and combined with this new upstream conversion technology (J. Han et al., 2015).

Recent studies suggest a number of alternatives for separating biomass-derived sugars from the GVL solvent (Han, Sen, Alonso, Dumesic, \& Maravelias, 2014). Upon generation, the biomassderived sugars can be separated from the GVL solvent, lignin, and biomass residues by multi-stage $\mathrm{CO}_{2}$ extraction, phase separation by salt addition, or multi-stage extraction using alkylphenol as a solvent (Sen, Henao, Braden, Dumesic, \& Maravelias, 2012).

After separation from sugars, the GVL solvent can be further separated from lignin and biomass residues by precipitation of solids or evaporation of GVL before recycle back to the sugarproduction reactors, while lignin and residues can be either sold as byproducts for revenue or used as fuels in the utility plant. Fermentable $\mathrm{C}_{5}$ - and $\mathrm{C}_{6}$ - sugars can be converted biologically to 5 wt $\%$ ethanol with engineered yeast strains at $303 \mathrm{~K}$, followed by a series of purification steps (Lau \& Dale, 2009; Luterbacher et al., 2014). While there are various technologies for the conversion of biomass-derived sugars to different fuels, fuel additives, or chemicals, we choose to study a sugarto-ethanol process to qualitatively compare it with the benchmark lignocellulosic ethanol process studied by NREL (Humbird et al., 2011). To study this process, we generate a superstructure that embeds all separation alternatives as well as alternative biomass feedstocks. 


\subsection{Unit Modeling}

Reactors are modeled using the surrogate model described in section 2.1.1 in which the conversion expression in eqn. (8) is determined from experimental results. Evaporators and solid/liquid separators are modeled based on short-cut methods using parameters obtained from experiments. Distillation columns are modeled using the Fenske-Underwood method. For the extraction units and $\mathrm{CO}_{2}$ recovery system, the surrogate models are presented in the next subsections, while additional details are given in the appendices.

\subsubsection{Extraction Units}

As mentioned previously, three extraction alternatives $\left(\mathrm{CO}_{2}\right.$, alkylphenol, and salt $)$ are available and embedded in the superstructure to separate dissolved sugars from GVL solvent. In both the $\mathrm{CO}_{2}$ and alkylphenol strategies, the inlet mixture is split into two phases. The organic phase consists of extraction solvent (super-critical $\mathrm{CO}_{2}$ or alkylphenol) and GVL along with the dissolved lignin and biomass residues, while the aqueous phase contains $\mathrm{C}_{5}$ - and $\mathrm{C}_{6}$ - sugars. The liquid-liquid extractions are carried out in multi-stage columns. A surrogate model is developed to relate the component recoveries $\left(\kappa_{i, n}^{k}\right)$ with the number of stages $(n)$ at given feed and solvent component flow conditions. The partition coefficients of all components determined from single-stage extraction experiments are used to map the compositions of the extract and raffinate streams onto the number of stages using the Kremser-Souders-Brown (KSB) equations as follow:

$$
\frac{X_{F, k}-X_{R, k}}{X_{F, k}-X_{S, k} / \xi_{k}}=\frac{\left(\varepsilon_{k}\right)^{n+1}-\varepsilon_{k}}{\left(\varepsilon_{k}\right)^{n+1}-1} \quad k \in \mathbf{K}^{\mathbf{E}}
$$

where $X_{F, k}, X_{R, k}$, and $X_{S, k}$ are mole fraction of component $k$ in the feed, raffinate, and solvent streams, respectively, $\xi_{k}$ is the partition coefficient of component $k \in \mathbf{K}^{\mathbf{E}}$ in the extractor, and $\varepsilon_{k}$ is the extract factor linearly related to $\xi_{k}$. A detailed description of this surrogate model is presented in Appendix B.

A linear multi-stage extraction unit model is then developed using the correlations between the component recoveries and the number of stages. The component molar flows of Feed, Solvent and Extract streams are each disaggregated into $N$ stages using eqns. (68) - (70).

$$
\begin{array}{rlrl}
F_{F, k}=\sum_{n} F_{F, k, n} & k \in \mathbf{K}^{\mathbf{E}} \\
F_{S, k}=\sum_{n} F_{S, k, n} & k \in \mathbf{K}^{\mathbf{E}} \\
F_{E, k}=\sum_{n} F_{E, k, n} & k \in \mathbf{K}^{\mathbf{E}}
\end{array}
$$

Big-M constraints (eqns. (71) - (73)) are introduced to enforce the disaggregated molar flows on each stage to zero if that number of stages is not selected $\left(Y_{i, n}^{m s e}=0\right)$. In other words, for each stream only one of the disaggregated flows can take non-zero value (bounded by a valid upper bound when the corresponding number of stage is selected, i.e. $Y_{i, n}^{m s e}=1$ ). 


$$
\begin{array}{cc}
F_{F, k, n} \leq \bar{F}_{F, k, n} Y_{i, n}^{m s e} & i \in \mathbf{I}^{\mathbf{E}}, k \in \mathbf{K}^{\mathbf{E}}, n \in \mathbf{N} \\
F_{S, k, n} \leq \bar{F}_{S, k, n} Y_{i, n}^{m s e} & i \in \mathbf{I}^{\mathbf{E}}, k \in \mathbf{K}^{\mathbf{E}}, n \in \mathbf{N} \\
F_{E, k, n} \leq \bar{F}_{E, k, n} Y_{i, n}^{m s e} & i \in \mathbf{I}^{\mathbf{E}}, k \in \mathbf{K}^{\mathbf{E}}, n \in \mathbf{N}
\end{array}
$$

Equation (74) relates the extract stream component flows to those in the feed and solvent streams. Note that if the multi-stage extraction unit is not selected $\left(Y_{i}^{\text {unit }}=0\right)$, all binary variables for the selection of the number of stages $\left(Y_{i, n}^{m s e}\right)$ will be zero (eqn. (75)), and therefore, all the aggregated and disaggregated component flows will be forced to zero as well using eqns. (68) - (70) and eqns. (71) - (73), respectively.

$$
\begin{gathered}
F_{E, k, n}=\kappa_{i, n}^{k}\left(F_{F, k, n}+F_{S, k, n}\right) \quad i \in \mathbf{I}^{\mathbf{E}}, k \in \mathbf{K}^{\mathbf{E}}, n \in \mathbf{N} \\
\sum_{n} Y_{i, n}^{m s e}=Y_{i}^{u n i t} \quad i \in \mathbf{I}^{\mathbf{E}}
\end{gathered}
$$

For salt extraction, sodium chloride $(\mathrm{NaCl})$ is added to partition the inlet mixture. In this case, we utilize a single stage extraction model in which the component split fractions are determined by experiments.

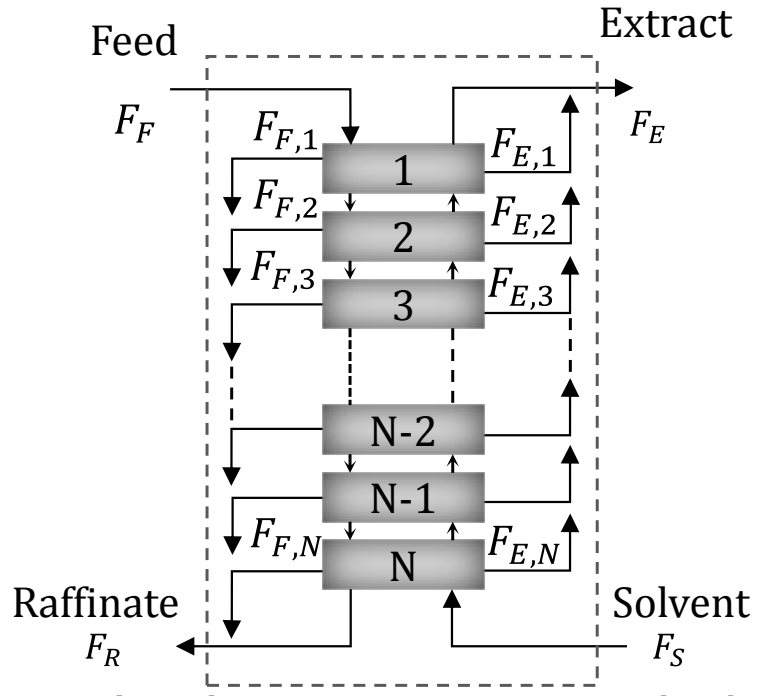

Figure 10. Selection of stages in the multi-stage extraction unit. Note that the index $i$ and $k$ are dropped.



Figure 11. $\mathrm{CO}_{2}$ recovery system. 


\subsection{2 $\mathrm{CO}_{2}$ Recovery System}

In the $\mathrm{CO}_{2}$ extraction strategies, liquid $\mathrm{CO}_{2}$ in the GVL-rich mixture has to be recovered and recycled. The mixture is sent to a $\mathrm{CO}_{2}$ recovery system which consists of five vapor-liquid separators connected in series with decreasing temperature and pressure (Figure 11).

The system is able to recover more than $86 \%$ of the $\mathrm{CO}_{2}$ (with over $99.5 \%$ purity) from the GVL-rich stream. Four compressors are used to recompress the $\mathrm{CO}_{2}$ recovered from the flash tanks. To estimate the electric power requirements for the compression, a surrogate model for the $\mathrm{CO}_{2}$ recovery system is developed using a process simulator (Aspen Plus). Note that we develop a surrogate model for an entire subsystem of units rather than for each unit in this subsystem which leads to significant reduction in the number of variables. In the surrogate model, power requirement $\left(W_{f_{1}}\right)$ is expressed as a function of total feed molar flow $\left(F^{i n}\right), \mathrm{CO}_{2}$ composition $\left(X_{C_{2} O_{2}}^{i n}\right)$, and recovery $\left(\Omega_{i, \mathrm{CO}_{2}}\right)$. Note that for each vapor-liquid separator, the operating pressure is optimized to minimize the total power requirement. All these independent variables are investigated to obtain their relationship with the power requirement. A piecewise linear function is used to approximate the relationship between $W_{f_{1}}$ and $\mathrm{CO}_{2}$ recovery (see Figure 12). In each domain $l, a_{l}$ and $b_{l}$ are constants from the approximated linear function, and the selection of domain $l$ is determined by binary variables $\left(Y_{l}^{p w}\right)$ if the $\mathrm{CO}_{2}$ recovery system is selected $\left(Y_{i}^{\text {unit }}=1\right)$. Therefore, an expression can be written to correlate the power requirement with total feed flow and $\mathrm{CO}_{2}$ composition using the base values, $F^{\text {base }}$ and $X_{\mathrm{CO}_{2}}^{\text {base }}$, respectively.

$$
\begin{gathered}
W_{f_{1}}=\left(\frac{X_{C O_{2}}^{\text {base }}}{X_{C O_{2}}^{\text {in }}}\right)\left(\frac{F^{\text {in }}}{F^{\text {base }}}\right) \sum_{l}\left(a_{l} G_{l}+b_{l} Y_{l}^{p w}\right) \\
\Omega_{f_{1}, C O_{2}}=\sum_{l} G_{l} \\
\sum_{l} Y_{l}^{p w}=Y_{i}^{\text {unit }} \\
Y_{l}^{p w} \underline{G}_{l} \leq G_{l} \leq Y_{l}^{p w} \bar{G}_{l} \quad l \in \mathbf{L}
\end{gathered}
$$

We see that the power requirement decreases with increasing $\mathrm{CO}_{2}$ concentration in the feed. This decrease is because high $\mathrm{CO}_{2}$ concentration in the feed benefits the $\mathrm{CO}_{2}$ recovery in the first flash tank, which operates at the same pressure level as the extraction unit, and thereby does not require compression prior to recycling. We also find that the power requirement scales with total feed molar flow.

\subsection{Design Base, Assumptions, and Objective}

The objective is to maximize the annualized profit, which takes into account the revenues from ethanol and by-products (lignin and excess electricity) sales, the cost of raw materials and utilities, and the annualized capital cost. Equipment costs are estimated from the power law expression (Sinnott, 2009). Annual operation is assumed to be 8,400 hours. Capital costs are annualized using a 
capital recovery factor ( $\mathrm{crf}$ ) of $11.75 \%$ based on a $10 \%$ discount rate and an equipment lifespan of 20 years. The price of ethanol is assumed to be $\$ 4$ per gallon and all prices are updated to 2012 prices based on the Chemical Engineering Index.

To be consistent with the benchmark NREL report, the processing capacity of our ethanol production plant is assumed 2,000 dry tons of biomass per day. We consider various type of biomass feedstock including corn stover, sugarcane, hybrid poplar, loblolly pine, aspen wood, wheat straw, and switchgrass, since the non-enzymatic biomass-to-sugar process is shown to be effective with various biomass types (Luterbacher et al., 2014). The composition of each feedstock is obtained from the U.S. Department of Energy database (Energy., 2014), and feedstock prices are taken from a previous study (Sen et al., 2012).

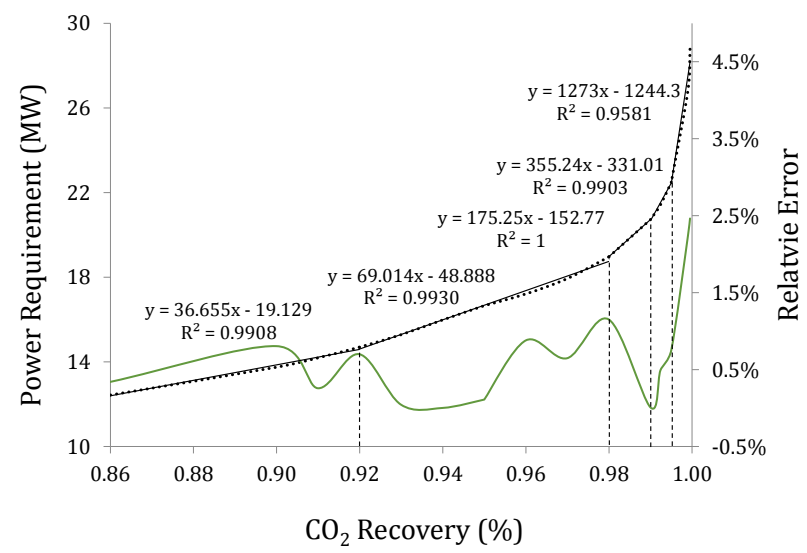

Figure 12. Linear approximation of the power requirement versus $\mathrm{CO}_{2}$ recovery. The green solid line represents the relative percentage errors of the approximation.

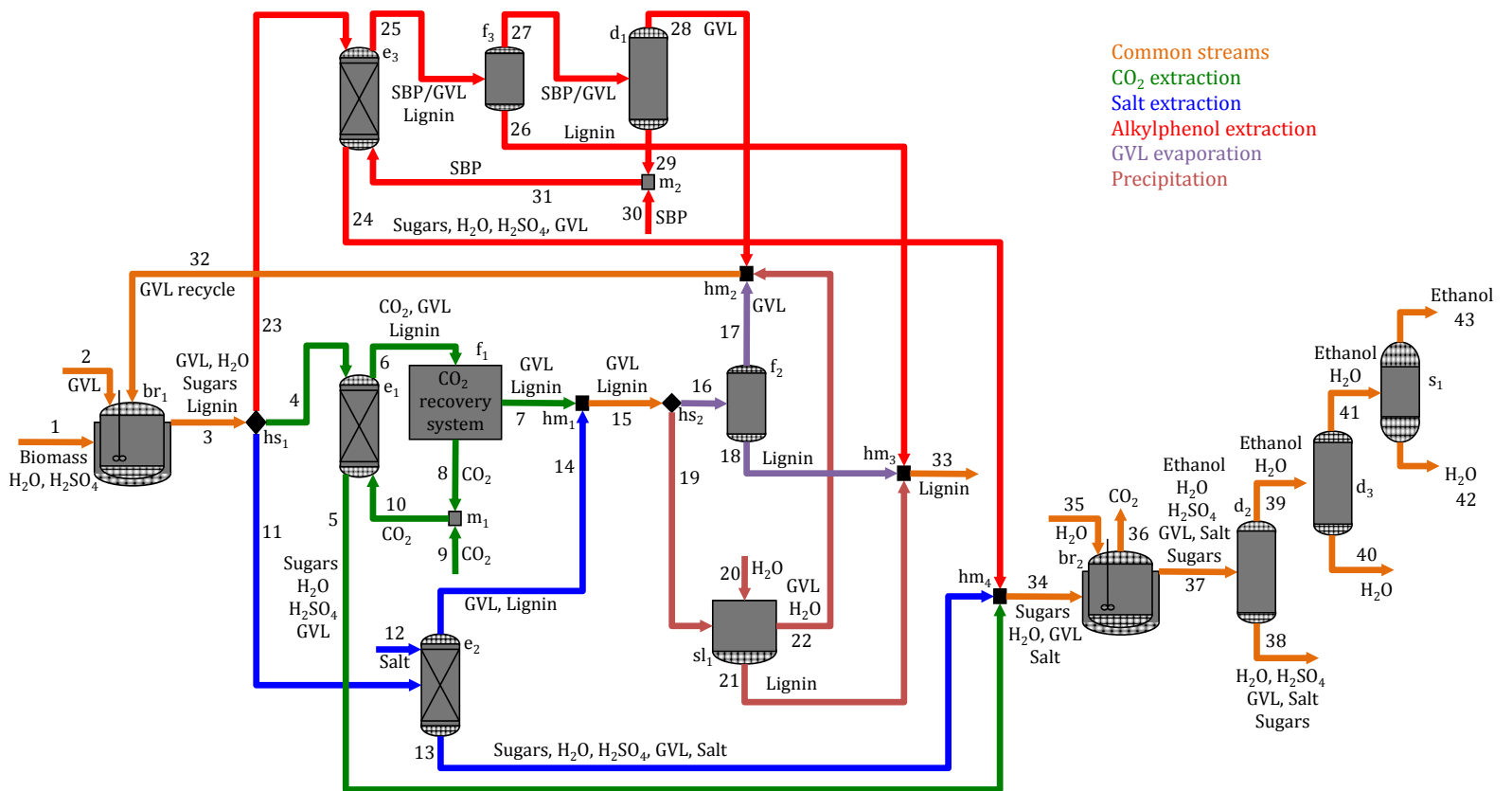

Figure 13. Superstructure for ethanol production. Streams are numbered and key components are shown for 
each stream. Streams for alternative strategies are shown in different colors while common streams are denoted in orange.

\subsection{Case-specific Bound Tightening}

In addition to adding the general bounds and redundant constraints mentioned in the previous sections, we generate tighter bounds for this particular case study to further improve the solution process. We analyze the upper bound on ethanol molar flow $\left(\bar{F}_{37, \text { ethanol }}\right)$ of the fermentation effluent (stream 37 in Figure 13). We first use the general bound propagation method that starts from the upper bounds on molar flow of cellulose $\left(\bar{F}_{1, \text { cellulose }}\right)$ and hemicellulose $\left(\bar{F}_{1, \text { hemicellulose }}\right)$ in the feed stream. We then propagate them through the biomass-to-sugar reactors $\left(\mathrm{br}_{1}\right)$, separation steps, and sugar-to-ethanol reactor $\left(\mathrm{br}_{2}\right)$. Note that different types of biomass contain different amount of cellulose and hemicellulose. Given a constant biomass processing capacity, $\bar{F}_{1, \text { cellulose }}$ is determined using the most cellulose-rich biomass (loblolly pine) as a feedstock, while $\bar{F}_{1, \text { hemicellulose }}$ is calculated by assuming the most hemicellulose-rich biomass (swithgrass) is used. However, only one type of biomass can be chosen in the superstructure model, and thereby $\bar{F}_{1, \text { cellulose }}$ and $\bar{F}_{1, \text { hemicellulose }}$ can never be reached simultaneously in any feasible solution. Therefore, an upper bound on ethanol flow in stream $37\left(\bar{F}_{37, e t h a n o l}^{\prime}\right)$ cannot be reached since it is calculated by bound propagations starting from $\bar{F}_{1, \text { cellulose }}$ and $\bar{F}_{1, \text { hemicellulose }}$ in the feedstock. To tighten this bound, we evaluate each type of biomass individually; i.e., we calculate the maximum ethanol molar flow in stream $37\left(\bar{F}_{37 \text {,ethanol }}^{k}\right)$ for each type of biomass $k \in \mathbf{K}^{\mathbf{L}}$ and then select the maximum of $\bar{F}_{37, \text { ethanol }}^{k}$ among all the biomass alternatives as the updated upper bound on ethanol molar flow $\left(\bar{F}_{37, \text { ethanol }}\right)$,

$$
\bar{F}_{37, \text { ethanol }}=\max _{k \in \mathbf{K}^{\mathrm{L}}}\left(\bar{F}_{37, \text { ethanol }}^{k}\right)
$$

Similar calculations are carried for other streams in the superstructure. In addition, other propagation methods are applied. For example, the upper bound on total raw material cost is not a simple summation of the upper bounds on all raw materials. Since some of the raw materials are not compatible (e.g. $\mathrm{CO}_{2}$, SBP, and salt) as a result of the superstructure alternatives, among these incompatible materials only the one with the largest upper bound on material cost is included in calculating the upper bound on the total raw material cost. Similarly, some of the units are also mutually exclusive (e.g. GVL evaporation $\left(\mathrm{f}_{1}\right)$ and solid/liquid separation $\left(\mathrm{sl}_{1}\right)$ ), thereby must be accounted for in calculating the upper bounds on capital and operating cost. The bound tightening relies on in-depth understanding of the particular superstructure as well as engineering judgement.

\subsection{Results}

Using BARON 14.4.0 through GAMS 24.4.5, we obtained a feasible solution, with profit=\$65 million/yr, after 9 hours of CPU time (optimality gap $=14 \%$ of revenue). The final configuration 
includes the non-enzymatic sugar production $\left(\mathrm{br}_{1}\right)$ followed by the multi-stage $\mathrm{CO}_{2}$ extraction $\left(\mathrm{e}_{1}\right)$ and $\mathrm{CO}_{2}$ recovery system $\left(\mathrm{f}_{1}\right)$ for sugar separation. $\mathrm{GVL}$ is separated from lignin and biomass residues using an evaporator $\left(f_{2}\right)$ before being recycled back to the sugar production reactors. After separation, sugars are sent to the fermentor $\left(\mathrm{br}_{2}\right)$ for ethanol production. The effluent stream of $\mathrm{br}_{2}$ is then sent to two distillation columns $\left(d_{2}\right.$ and $\left.d_{3}\right)$ connected in series for ethanol purification. Finally, an azeotrope distillation column $\left(\mathrm{s}_{1}\right)$ is used to obtain ethanol product at $99.6 \mathrm{wt} \%$ purity (see Figure 14).

Corn stover was selected as the biomass feedstock. The annual feedstock cost ( $\$ 58.1$ million) is the largest cost contributor accounting for $64 \%$ of the operation cost. The second largest contributor is the cost of make-up GVL ( $\$ 30$ million/yr at $\$ 120 /$ ton GVL), which accounts for 33\% of the operation cost. Therefore, a low GVL-to-biomass ratio (14:1 wt\%) is selected despite leading to lower $\mathrm{C}_{5}$-sugar yield. The multi-stage extraction unit is able to recover $99.5 \%$ of the GVL solvent using an extraction column with three stages. Following the multi-stage extraction, the optimal $\mathrm{CO}_{2}$ recovery is found to be $86 \%$ in the $\mathrm{CO}_{2}$ recovery system, leading to a power demand of $12.3 \mathrm{MW}$. The fermentation reactors convert $87 \%$ of the sugars to ethanol. After purification, the selected process yields $46.9 \mathrm{mmgal} / \mathrm{yr}$ of ethanol, resulting in an annual revenue of $\$ 187$ million at a price of $\$ 4 /$ gal ethanol. The ethanol yield in our process is 64 gallon per ton of feedstock. In the selected configuration, lignin and biomass residues are used as fuels in the utility plant instead of selling at a price of $\$ 50 /$ ton for revenue.

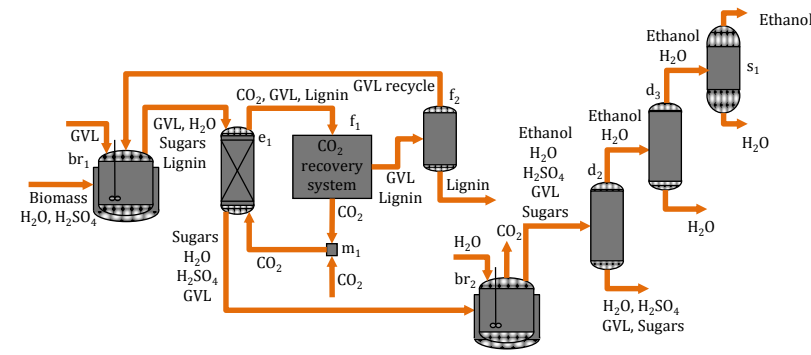

Figure 14. Selected configuration of ethanol production process.

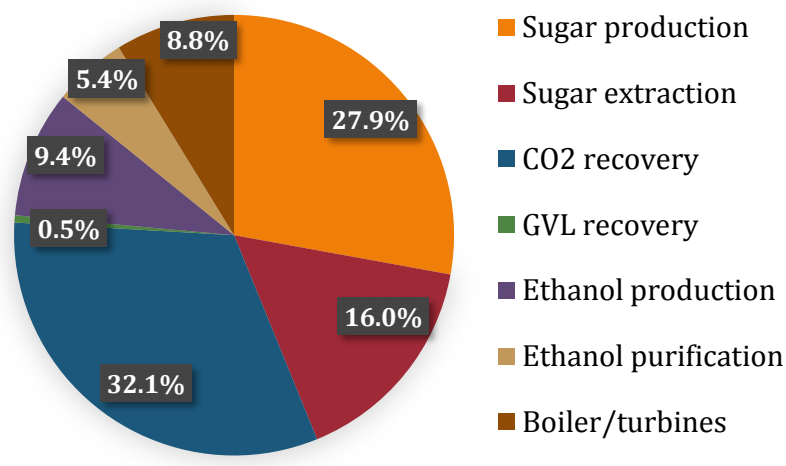


Figure 15. Total capital investment breakdown for the ethanol production process.

The total heating requirement of the selected configuration before heat integration is $259 \mathrm{MW}$. The heat integration with 9 temperature intervals recovers $16 \mathrm{MW}$. The remaining heating requirement (243 MW) is satisfied by HP steam generated in the utility plant.

The boiler produces $132 \mathrm{~kg} / \mathrm{s}$ of HP steam (at $30 \mathrm{bar}, 750 \mathrm{~K}$ ) using the heat released from the combustion of lignin and biomass residues. HP/WT vacuum turbine is installed to satisfy the power requirement of the entire process $(12.4 \mathrm{MW})$ while the excess bio-electricity $(9.4 \mathrm{MW})$ is sold to the grid (total electricity credit is $\$ 5.9 \mathrm{MM} / \mathrm{yr}$ ).

The annualized total capital investment was found to be $\$ 37.9$ million, of which the $\mathrm{CO}_{2}$ recovery system (including compressors and flash tanks) is the largest cost contributor (accounting for 32\% of the total capital investment). The non-enzymatic sugar production system is another major cost contributor that accounts for $28 \%$ of the total capital investment (see Figure 15).

\section{Conclusions}

We proposed a superstructure-based modeling and optimization framework for simultaneous process synthesis, heat integration, and utility plant design. The framework accounts for the interactions among all three subsystems, allowing us to quickly generate and evaluate a wide range of strategies. Notably, the proposed framework considers variable heat duties at the main chemical facility as well as variable steam temperatures and pressures at the utility subsystem. To enhance the solution of the resulting MINLP models, we developed a number of modeling and solution methods. First, we presented a reformulation that allows the deactivation of unit models via the molar flows of the inlet streams, thereby avoiding the generation of highly nonlinear reformulations. Second, surrogate models generated from offline simulations or experimental data are used when the first-principles unit models are too complex or are not available. Third, we formulated new equations for the calculation of steam properties. Fourth, we developed bound propagation techniques for the calculation of variable bounds. Finally, we proposed methods to systematically generate redundant constraints that can speed up the solution of the resulting models. Through a case study, we showed that the proposed framework allows us to study systems with a large number of embedded designs while employing accurate unit models.

\section{Acknowledgements}

This work was funded by the DOE Great Lakes Bioenergy Research Center (DOE BER Office of Science DE-FC02-07ER64494). 


\section{Notation}

\section{Sets}

$i \in \mathbf{I}$

units

$j \in \mathbf{J}$

process streams

$k \in \mathbf{K}$

components

$m \in \mathbf{M}$

temperature intervals

$n \in \mathbf{N}$

number of stages in a multi-stage extraction units

$r \in \mathbf{R}$

reactions

$u \in \mathbf{U}$

utilities for cooling/heating

\section{Subsets}

$\mathrm{J}^{\mathrm{C}} / \mathrm{J}^{\mathrm{H}}$

$\mathbf{J}^{\mathrm{UN}} / \mathbf{J}^{\mathrm{US}}$

$\mathbf{J}_{i}$

$\mathbf{J}_{i}^{\mathbf{I N}} / \mathbf{J}_{i}^{\mathbf{O U T}}$

$\mathbf{U}^{S}$

$\mathbf{U}^{\mathbf{N}}$

\section{Parameters}

$\Delta S^{\text {cond }}$

$\Delta T^{\text {min }}$

$\eta_{i}$

$\kappa_{i, n}^{k}$

$v_{r, k}$

$\xi_{i, k}$

$C p_{j}$

$h^{\text {cond }}$

$L H V_{k}$

$R^{\text {univ }}$ cold/hot process streams

cold/hot utility streams

streams connected to unit $i$

set of all inlet/outlet streams of unit $i$

utilities for heating

utilities for cooling

\section{Continuous Variables}

$\gamma_{u, u^{\prime}}$

$\delta_{u, u^{\prime}}^{+}, \delta_{u, u^{\prime}}^{-}$

$\epsilon_{u, u^{\prime}}^{+}, \epsilon_{u, u^{\prime}}^{-}$

$\Omega_{i, k}$

$A C_{i}$

$C_{r}$

CC

$F_{j, k}$

$F_{j}^{T}$

$H_{j}$ entropy of condensation of steam (kJ/kg.K)

minimum temperature difference for heat exchange $(\mathrm{K})$

efficiency of unit $i$

recovery of component $k$ if $n$ stages are selected for multi-stage extraction unit $i$

stoichiometric coefficient of component $k$ in reaction $r$

partition coefficient of component $k$ in extraction unit $i$

specific heat capacity of process stream $j(\mathrm{~kJ} / \mathrm{kg} \cdot \mathrm{K})$

latent heat of condensation of the wet steam $(\mathrm{kJ} / \mathrm{kg})$

lower heating value of component $k(\mathrm{~kJ} / \mathrm{kg})$

universal gas constant $(\mathrm{kJ} / \mathrm{kmol} \cdot \mathrm{K})$

expansion coefficient of turbine (inlet steam $u$ \& outlet steam $u^{\prime}$ )

deviation variables for isentropic expansion

deviation variables for isenthalpic expansion

component recovery of $k$ in separation unit $i$

annualized capital cost of unit $i$

conversion of the limiting component in reaction $r$

total annualized capital cost (MM\$/yr)

molar flow rate of component $k$ in stream $j$

total molar flow rate of stream $j$

enthalpy of stream $j(\mathrm{~kJ} / \mathrm{kg})$ 


$\begin{array}{ll}O C & \text { operating cost (MM\$ } / \mathrm{yr}) \\ P_{j} & \text { pressure of stream } j \text { (bar) } \\ P_{j}^{r e d} & \text { reduced pressure of stream } j \\ Q^{\text {cond }} & \text { cooling required for condensation of the wet steam }(\mathrm{kW}) \\ Q_{i} & \text { Heat loads for unit } i \\ Q_{j}^{h} & \text { Heat available in hot utility stream } j(\mathrm{~kW}) \\ Q_{j, m}^{h} / Q_{j, m}^{c} & \text { heat provided/received by hot } / \text { cold stream } j \text { in interval } m(\mathrm{~kW}) \\ Q R_{m} & \text { residual heat from interval } m \text { to interval } m+1(\mathrm{~kW}) \\ T_{j} & \text { temperature of stream } j(\mathrm{~K}) \\ T_{j}^{\text {red }} & \text { reduced temperature of stream } j \\ T_{j, m}^{h} & \text { temperature of hot utility stream } j \text { in interval } m(\mathrm{~K}) \\ T_{u}^{\text {sat }} & \text { saturation temperature of steam } u(\mathrm{~K}) \\ T C / T R & \text { total production costs } / \text { revenues } \\ W^{\text {demand }} & \text { electricity demand (kW) } \\ W^{\text {purchase }} & \text { amount of electricity purchased }(\mathrm{kW}) \\ W^{\text {sale }} & \text { excess electricity sales }(\mathrm{kW}) \\ W_{i} & \text { power requirement of unit } i(\mathrm{~kW}) \\ X_{j, k} & \text { mole fraction of component } k \text { in stream } j \\ Z_{u} & \text { compressibility factor of steam } u\end{array}$

\section{Binary Variables}

$Y_{i}^{\text {unit }} \quad=1$ if unit $i$ is selected

$Y_{i, n}^{m s e} \quad=1$ if there are $n$ stages in the multi-stage extraction unit $i$

$Y_{j, m} \quad=1$ if temperature of steam $j$ is in interval $m$ 


\section{Appendices}

\section{A. Reformulation of General Flow-based Unit Model}

Using the reformulation method presented in eqn. (9), the reformulation of flow-based generic model $(i \in \mathbf{I})$ is shown as follows:

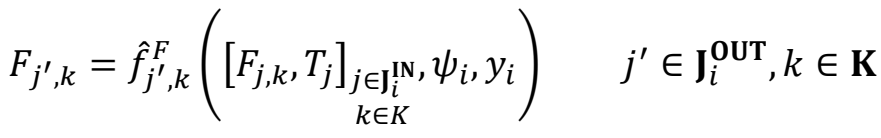

$$
\begin{aligned}
& T_{j^{\prime}}=\hat{f}_{j^{\prime}}^{T}\left(\left[F_{j, k}, T_{j}\right]_{\substack{j \in \mathbf{J}_{i}^{\mathrm{IN}} \\
k \in K}}, \psi_{i}, y_{i}\right) \quad j^{\prime} \in \mathbf{J}_{i}^{\text {OUT }} \\
& Q_{l, i}=\hat{f}_{l, i}^{Q}\left(\left[F_{j, k}, T_{j}\right]_{\substack{j \in \mathbf{J}_{i}^{\mathbf{I N}} \\
k \in K}}, \psi_{i}, y_{i}\right) \quad l \in \mathbf{L}_{i}^{\mathbf{Q}} \\
& W_{l, i}=\hat{f}_{o, i}^{W}\left(\left[F_{j, k}, T_{j}\right]_{\substack{j \in \mathbf{J}_{i}^{\mathrm{IN}} \\
k \in K}}, \psi_{i}, y_{i}\right) \quad l \in \mathbf{L}_{i}^{\mathbf{W}} \\
& C c_{i}=\hat{f}^{C c}\left(\left[F_{j, k}, T_{j}\right]_{\substack{j \in \mathbf{J}_{i}^{\mathrm{IN}} \\
k \in K}}, \psi_{i}, y_{i}\right) \\
& C o_{i}=\hat{f}^{C o}\left(\left[Q_{l, i}\right]_{l \in \mathbf{L}_{i}^{\mathrm{Q}},}\left[W_{o, i}\right]_{o \in \mathbf{L}_{i}^{\mathrm{W}}}, y_{i}\right) \\
& \underline{F}_{j, k} \cdot y_{i} \leq F_{j, k} \leq \bar{F}_{j, k} \cdot y_{i} \quad j \in \mathbf{J}_{i}^{\mathbf{I N}}, k \in \mathbf{K} \\
& \underline{T}_{j} \cdot y_{i} \leq T_{j} \leq \bar{T}_{j} \cdot y_{i} \quad j \in \mathbf{J}_{i}^{\mathbf{I N}} \\
& \underline{\psi_{i}} \cdot y_{i} \leq \psi_{i} \leq \bar{\psi}_{i} \cdot y_{i}
\end{aligned}
$$

where $\underline{F}_{j, k}, \bar{F}_{j, k}, \underline{T}_{j}, \bar{T}_{j}$, and $\underline{\psi}_{i}, \bar{\psi}_{i}$ are lower and upper bounds on the corresponding variables. 


\section{B. Surrogate Models}

\section{B.1 Multi-stage Extraction}

In a multi-stage extraction unit (Figure 10), component material balances can be written as follows:

$$
F_{F, k}+F_{S, k}=F_{R, k}+F_{E, k} \quad k \in \mathbf{K}^{\mathbf{E}}
$$

where $F_{F, k}, F_{S, k}, F_{R, k}$, and $F_{E, k}$ are component molar flow rate in the feed $(F)$, solvent $(S)$, raffinate $(R)$, and extract $(E)$ stream, respectively. Mole fraction of component $k$ in stream $j \in \mathbf{J}^{\mathbf{E}}=$ $\{F, S, R, E\}$ is calculated in equations (B.2) and (B.3),

$$
\begin{aligned}
F_{j}^{T} & =\sum_{k} F_{j, k} \quad j \in \mathbf{J}^{\mathbf{E}} \\
X_{j, k} F_{j}^{T} & =F_{j, k} \quad k \in \mathbf{K}^{\mathbf{E}}, j \in \mathbf{J}^{\mathbf{E}}
\end{aligned}
$$

where $F_{j}^{T}$ represents the total molar flow in stream $j$. The following Kremser-Souders-Brown (KSB) equation relates the mole fractions of solutes with the number of stages,

$$
\frac{X_{F, k}-X_{R, k}}{X_{F, k}-X_{S, k} / \xi_{k}}=\frac{\left(\varepsilon_{k}\right)^{n+1}-\varepsilon_{k}}{\left(\varepsilon_{k}\right)^{n+1}-1} \quad k \in \mathbf{K}^{\mathbf{E}} \backslash\{\text { solvents }\}
$$

where $\xi_{k}$ is the partition coefficient of component $k$ that relates the compositions of extract and raffinate streams .

$$
X_{E, k}=\xi_{k} X_{R, k} \quad k \in \mathbf{K}^{\mathbf{E}}
$$

and $\varepsilon_{k}$ is the extraction factor of component $k$ calculated from the following equation,

$$
\varepsilon_{k}=\xi_{k} \frac{\sum_{k \in\left\{\text { solvents } F_{S, k}\right.}}{\sum_{k \in\{\text { solvents }\}} F_{F, k}} \quad k \in \mathbf{K}^{\mathbf{E}}
$$

where $\sum_{k \in\{\text { solvents }\}} F_{S, k}$ and $\sum_{k \in\{\text { solvents }\}} F_{F, k}$ stand for the total molar flow of the solvent and feed stream in a solute-free basis, respectively. Finally, the following equation for raffinate flow is

\begin{tabular}{|c|c|c|}
\hline \multirow{2}{*}{ Number of stages $(n)$} & \multicolumn{2}{|c|}{ GVL recovery in } \\
\hline & Liquid $\mathrm{CO}_{2}$ & Alkylphenol \\
\hline 1 & $89.72 \%$ & $85.17 \%$ \\
\hline 2 & $97.75 \%$ & $94.55 \%$ \\
\hline 3 & $99.44 \%$ & $97.85 \%$ \\
\hline 4 & $99.81 \%$ & $99.13 \%$ \\
\hline 5 & $99.89 \%$ & $99.64 \%$ \\
\hline 6 & $99.91 \%$ & $99.85 \%$ \\
\hline 7 & $99.91 \%$ & $99.94 \%$ \\
\hline 8 & $99.91 \%$ & $99.97 \%$ \\
\hline
\end{tabular}
included and closes the degree of freedom.

$$
F_{R, k}=X_{R, k} \sum_{k \in\{\text { solvents }\}} F_{F, k} \quad k \in \mathbf{K}^{\mathbf{E}}
$$

Equations (B.1) - (B.7) are used to develop the surrogate models for GVL recovery in the liquid $\mathrm{CO}_{2}$ and alkylphenol multi-stage extractions. The results are shown in Table B.1 and used in eqn. (74). 


\section{B.2 $\mathrm{CO}_{2}$ Recovery Subsystem}

The electric power requirements from the compressors in the $\mathrm{CO}_{2}$ recovery system are modeled using ASPEN process simulator. Five flash tanks are connected in series with reducing pressure. Compressors are used to repressurize the vapor phase from each tank for recycling back to the extraction unit. By changing the total feed flow, $\mathrm{CO}_{2}$ composition, and recovery, we express the total power consumption as a function of these variables. Minimum power consumption is obtained for each simulation using the optimization feature in Aspen Plus which optimizes the operating pressure of the flash vessels.

The power requirement increases with the $\mathrm{CO}_{2}$ recovery. The power requirement is also shown to be sensitive to both $\mathrm{CO}_{2}$ feed concentration and total molar flow rate at the inlet. A base case is first developed assuming constant $\mathrm{CO}_{2}$ feed concentration $\left(\mathrm{X}_{\mathrm{CO}_{2}}^{\text {base }}\right)$ and inlet flow $\left(F^{\text {base }}\right)$. Power requirements in the base case are calculated at various $\mathrm{CO}_{2}$ recovery levels and the correlation is represented by a piecewise linear function (see Figure 12). Then, we determine the power requirements at different $\mathrm{CO}_{2}$ feed concentration $\left(X_{\mathrm{CO}_{2}}^{i n}\right)$ and inlet flow rates $\left(F^{i n}\right)$ by rescaling the base-case power requirement using the $\mathrm{CO}_{2}$ concentration and inlet flow ratios with respect to those in the base case (eqn. (77)).
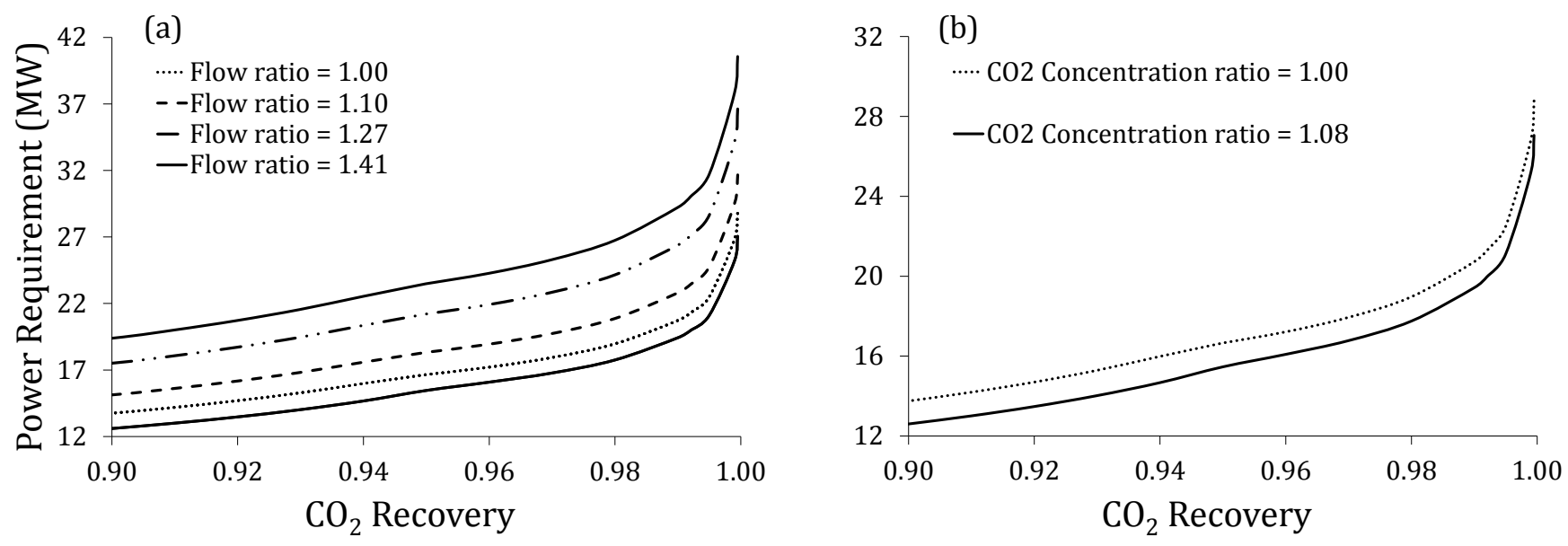

Figure B.1. Power requirement versus (a) $\mathrm{CO}_{2}$ recovery at various inlet flow ratios with respect to that in the base case $\left(F^{\text {in }} / F^{\text {base }}\right)$ at fixed $\mathrm{CO}_{2}$ feed concentration $\left(\mathrm{X}_{\mathrm{CO}_{2}}^{\text {base }}\right)$, and (b) $\mathrm{CO}_{2}$ recovery at various $\mathrm{CO}_{2}$ feed concentration ratios with respect to that in the base case $\left(X_{\mathrm{CO}_{2}}^{\text {in }} / X_{\mathrm{CO}_{2}}^{\text {base }}\right)$ at fixed total inlet flow rate $\left(F^{\text {base }}\right)$. 


\section{Steam and Condensate Properties}

\section{C.1 Condensate Heat Capacity and Enthalpy}

The constants for the Shomate equation (eqns. (47) and (48)) are tabulated in Table C.1.

\begin{tabular}{cr} 
Table C.1. Constants for the Shomate equatio \\
$\begin{array}{cr}\text { Temperature } \\
\text { Range (K) }\end{array}$ & $298-500$ \\
\hline$a^{c p}$ & -203.61 \\
$b^{c p}$ & 1523.29 \\
$c^{c p}$ & -3196.41 \\
$d^{c p}$ & 2474.46 \\
$e^{c p}$ & 3.86 \\
$f^{c p}$ & -256.55 \\
$h^{c p}$ & -285.83 \\
\hline
\end{tabular}

The linear approximation of eqn. (47) is plotted in Figure C.1a for the estimation of heat capacity of the condensates of each steam type as a function of saturation temperature at the given temperature range.

The specific enthalpy of the liquid stream at the boiler inlet $\left(H\left(T_{b i n}\right)\right)$ due to sensible heat is calculated by the linear approximation of eqn. (48) as shown in Figure C.1b.
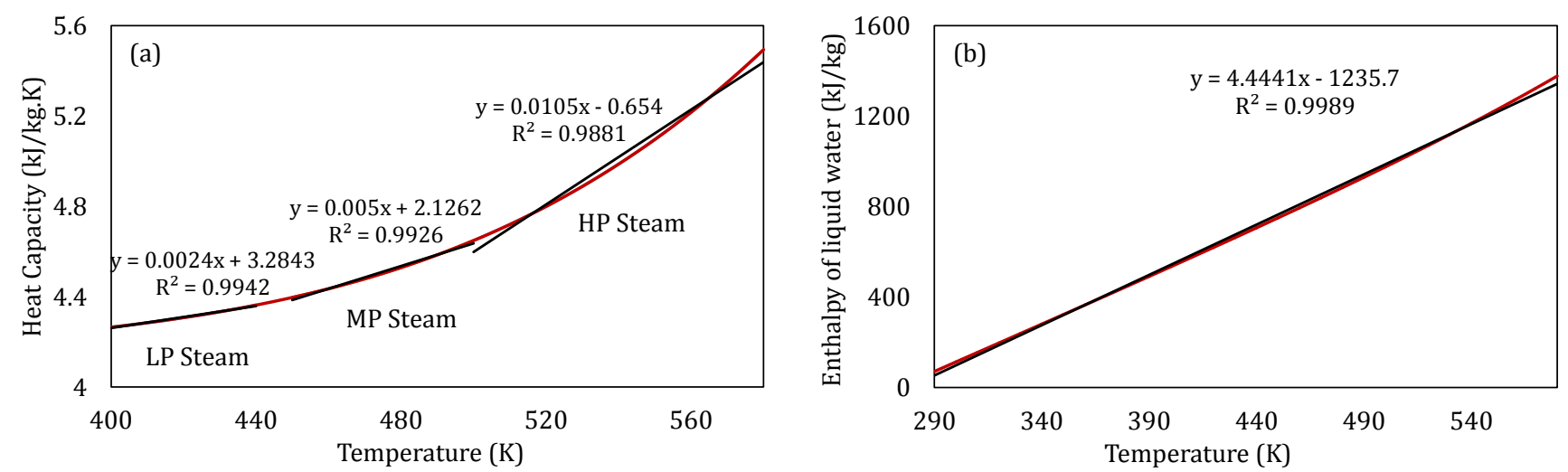

Figure C.1. Linear approximation of (a) heat capacity of the steam condensate, and (b) enthalpy of the liquid mixture at the boiler inlet.

\section{C.2 Density of Condensed Phase}

The density of steam condensates $\left(\rho_{u}\right)$ at the saturation temperature $\left(T_{u}^{\text {sat }}\right.$ calculated using Antoine equation) and steam pressure $\left(P_{u}\right)$ can be estimated by the following correlation.

$$
\rho_{u}=\frac{\rho^{0}}{\left[1+\beta_{u}\left(T_{u}^{s a t}-T^{0}\right)\right]\left[1-\left(P_{u}-P^{0}\right) / B\right]} \quad u \in \mathbf{U}^{\mathbf{S}}
$$

where $\rho^{0}$ denotes the density of water at the reference state $\left(T^{0}, P^{0}\right), \beta_{u}$ is the expansion coefficient of the saturated liquid corresponds to each type of steam $u$, and $B$ is the bulk modulus of water. The average density for condensate of each type steam is calculated and tabulated in Table C.1. 
Table C.1. Density Calculation for the Condensed Phase

\begin{tabular}{|c|c|c|c|c|}
\hline & $\begin{array}{l}\text { Pressure } \\
\text { (bar) }\end{array}$ & $\begin{array}{c}\text { Temperature } \\
(\mathrm{K})\end{array}$ & $\begin{array}{l}\text { Density } \\
\left(\mathrm{kg} / \mathrm{m}^{3}\right)\end{array}$ & $\begin{array}{c}\text { Average Density } \\
\left(\mathrm{kg} / \mathrm{m}^{3}\right)\end{array}$ \\
\hline \multirow{2}{*}{ HP Steam } & 30 & 506.9 & 819.2 & \multirow{2}{*}{799.0} \\
\hline & 90 & 577.4 & 778.9 & \\
\hline \multirow{2}{*}{ MP Steam } & 10 & 453.0 & 864.9 & \multirow{2}{*}{851.3} \\
\hline & 25 & 497.0 & 837.8 & \\
\hline \multirow{2}{*}{ LP Steam } & 3 & 406.7 & 920.0 & \multirow{2}{*}{913.3} \\
\hline & 6 & 431.9 & 906.5 & \\
\hline \multirow{2}{*}{ WT Steam } & 0.02 & 290.8 & 991.0 & \multirow{2}{*}{975.8} \\
\hline & 0.5 & 354.5 & 960.7 & \\
\hline
\end{tabular}




\section{Case Study Information}

The main chemical reactions and the molecular formulas of the chemicals are tabulated in Table D.1 and Table D.2. The modeling approaches for the major processing units are shown in Table D.3. Prices of all materials are given in Table D.4. All the main assumptions are included in Table D.5.

Table D.1 Main reactions $(r \in \mathbf{R})$ in the ethanol production process

\begin{tabular}{c|c}
\hline Reactions & Reaction descriptions \\
\hline$r_{1}$ & $\mathrm{C}_{6} \mathrm{H}_{10} \mathrm{O}_{5}+\mathrm{H}_{2} \mathrm{O} \rightarrow \mathrm{C}_{6} \mathrm{H}_{12} \mathrm{O}_{6}$ \\
$r_{2}$ & $\mathrm{C}_{6} \mathrm{H}_{10} \mathrm{O}_{5} \rightarrow$ humins \\
$r_{3}$ & $\mathrm{C}_{5} \mathrm{H}_{8} \mathrm{O}_{4}+\mathrm{H}_{2} \mathrm{O} \rightarrow \mathrm{C}_{5} \mathrm{H}_{10} \mathrm{O}_{5}$ \\
$r_{4}$ & $\mathrm{C}_{5} \mathrm{H}_{8} \mathrm{O}_{4} \rightarrow$ humins \\
$r_{5}$ & $\mathrm{C}_{6} \mathrm{H}_{12} \mathrm{O}_{6} \rightarrow 2 \mathrm{C}_{2} \mathrm{H}_{6} \mathrm{O}+2 \mathrm{CO}_{2}$ \\
$r_{6}$ & $3 \mathrm{C}_{5} \mathrm{H}_{10} \mathrm{O}_{5} \rightarrow 5 \mathrm{C}_{2} \mathrm{H}_{6} \mathrm{O}+5 \mathrm{CO}_{2}$ \\
\hline
\end{tabular}

Table D.2 Main chemical species involved in the reactions

\begin{tabular}{c|c}
\hline Chemical names & Molecular formula \\
\hline Cellulose & $\mathrm{C}_{6} \mathrm{H}_{10} \mathrm{O}_{5}$ \\
Hemicellulose & $\mathrm{C}_{5} \mathrm{H}_{8} \mathrm{O}_{4}$ \\
$\mathrm{C}_{5}$-Sugars & $\mathrm{C}_{5} \mathrm{H}_{10} \mathrm{O}_{5}$ \\
$\mathrm{C}_{6}$-Sugars & $\mathrm{C}_{6} \mathrm{H}_{12} \mathrm{O}_{6}$ \\
Ethanol & $\mathrm{C}_{2} \mathrm{H}_{6} \mathrm{O}$ \\
\hline
\end{tabular}

Table D.3 Modeling approaches for major units in the ethanol production plant

\begin{tabular}{c|c}
\hline Unit descriptions & Unit models \\
\hline Reactors & Conversion-based surrogates \\
Evaporators/separators & Shortcut methods \\
Multistage extraction units & Surrogate models \\
Single stage extraction units & Shortcut methods \\
$\mathrm{CO}_{2}$ recovery system & Surrogate models \\
Distillation columns & Fenske-Underwood method \\
\hline
\end{tabular}

Table D.4 Material prices in the ethanol production plant

\begin{tabular}{c|c}
\hline Materials & Prices $(\$ /$ ton $)$ \\
\hline $\mathrm{CO}_{2}$ & 23.0 \\
ethanol & $1340(\$ 4 /$ gal $)$ \\
$\mathrm{GVL}$ & 120 \\
$\mathrm{H}_{2} \mathrm{O}$ & 0.0148 \\
$\mathrm{H}_{2} \mathrm{SO} 4$ & 35.0 \\
lignin & 50.0 \\
$\mathrm{NaCl}$ & 60.0 \\
$\mathrm{SBP}$ & 80.0 \\
\hline
\end{tabular}

Table D.5 Summary of process assumptions

\begin{tabular}{c|c}
\hline Name & value \\
\hline Operation mode $($ aoh $)$ & 8,400 hour $/ \mathrm{yr}$ \\
Capital recovery factor $(c r f)$ & $11.75 \%$ \\
Discount rate & $10 \%$ \\
Equipment life span & $20 \mathrm{yr}$ \\
Plant capacity $(\mu)$ & 2,000 ton dry biomass/day \\
Lang factor & 3.1 \\
\hline
\end{tabular}




\section{References}

Achenie, L. K. E., \& Biegler, L. T. (1990). A Superstructure Based Approach to Chemical Reactor Network Synthesis. Computers \& Chemical Engineering, 14(1), 23-40. doi:Doi 10.1016/00981354(90)87003-8

Achterberg, T. (2009). SCIP: solving constraint integer programs. Mathematical Programming Computation, 1(1), 1-41. doi:10.1007/s12532-008-0001-1

Aggarwal, A., \& Floudas, C. A. (1990). Synthesis of General Distillation Sequences - Nonsharp Separations. Computers \& Chemical Engineering, 14(6), 631-653. doi:Doi 10.1016/00981354(90)87033-L

Aguilar, O., Perry, S. J., Kim, J. K., \& Smith, R. (2007). Design and optimization of flexible utility systems subject to variable conditions - Part 1: Modelling framework. Chemical Engineering Research \& Design, 85(A8), 1136-1148. doi:10.1205/cherd06062

Barnicki, S. D., \& Siirola, J. J. (2004). Process synthesis prospective. Computers \& Chemical Engineering, 28(4), 441-446. doi:10.1016/j.compchemeng.2003.09.030

Bausa, J., Von Watzdorf, R., \& Marquardt, W. (1998). Shortcut methods for nonideal multicomponent distillation: 1. Simple columns. Aiche Journal, 44(10), 2181-2198. doi:DOI 10.1002/aic.690441008

Bruggemann, S., \& Marquardt, W. (2011). Conceptual Design of Distillation Processes for Mixtures with Distillation Boundaries: I. Computational Assessment of Split Feasibility. Aiche Journal, 57(6), 1526-1539. doi:10.1002/aic.12378

Bruno, J. C., Fernandez, F., Castells, F., \& Grossmann, L. E. (1998). A rigorous MINLP model for the optimal synthesis and operation of utility plants. Chemical Engineering Research \& Design, 76(A3), 246-258. doi:Doi 10.1205/026387698524901

Caballero, J. A., \& Grossmann, I. E. (2008). An algorithm for the use of surrogate models in modular flowsheet optimization. Aiche Journal, 54(10), 2633-2650. doi:10.1002/aic.11579

Caballero, J. A., Navarro, M. A., Ruiz-Femenia, R., \& Grossmann, I. E. (2014). Integration of different models in the design of chemical processes: Application to the design of a power plant. Applied Energy, 124, 256-273. doi:10.1016/j.apenergy.2014.03.018

Colmenares, T. R., \& Seider, W. D. (1989). Synthesis of Utility Systems Integrated with Chemical Processes. Industrial \& Engineering Chemistry Research, 28(1), 84-93. doi:DOI 10.1021/ie00085a015

Conde-Mejia, C., Jimenez-Gutierrez, A., \& El-Halwagi, M. M. (2013). Assessment of Combinations between Pretreatment and Conversion Configurations for Bioethanol Production. Acs Sustainable Chemistry \& Engineering, 1(8), 956-965. doi:10.1021/sc4000384

Energy., U. S. D. o. (2014). Biomass Feedstock Composition and Property Database Retrieved from http://www.afdc.energy.gov/biomass/progs/search1.cgi. $\quad$ Retrieved 8/18/2015 http://www.afdc.energy.gov/biomass/progs/search1.cgi

Floudas, C. A., Ciric, A. R., \& Grossmann, I. E. (1986). Automatic Synthesis of Optimum HeatExchanger Network Configurations. Aiche Journal, 32(2), 276-290. doi:DOI 10.1002/aic.690320215

Floudas, C. A., \& Paules, G. E. (1988). A Mixed-Integer Nonlinear-Programming Formulation for the Synthesis of Heat-Integrated Distillation Sequences. Computers \& Chemical Engineering, 12(6), 531-546. doi:Doi 10.1016/0098-1354(88)87003-0

Francisco, A. P. O., \& Matos, H. A. (2004). Multiperiod synthesis and operational planning of utility systems with environmental concerns. Computers \& Chemical Engineering, 28(5), 745-753. doi:10.1016/j.compchemeng.2004.02.025

Friedler, F., Tarjan, K., Huang, Y. W., \& Fan, L. T. (1992). Graph-Theoretic Approach to Process Synthesis - Axioms and Theorems. Chemical Engineering Science, 47(8), 1973-1988. doi:Doi 10.1016/0009-2509(92)80315-4 
Han, J., Luterbacher, J. S., Alonso, D. M., Dumesic, J. A., \& Maravelias, C. T. (2015). A lignocellulosic ethanol strategy via nonenzymatic sugar production: Process synthesis and analysis. Bioresource Technology, 182, 258-266. doi:http://dx.doi.org/10.1016/i.biortech.2015.01.135

Han, J., Sen, S. M., Alonso, D. M., Dumesic, J. A., \& Maravelias, C. T. (2014). A strategy for the simultaneous catalytic conversion of hemicellulose and cellulose from lignocellulosic biomass to liquid transportation fuels. Green Chemistry, 16(2), 653-661. doi:10.1039/C3GC41511B

Han, J., Sen, S. M., Luterbacher, J. S., Alonso, D. M., Dumesic, J. A., \& Maravelias, C. T. (2015). Process systems engineering studies for the synthesis of catalytic biomass-to-fuels strategies. Computers \& Chemical Engineering, 81, 57-69. doi:10.1016/j.compchemeng.2015.04.007

Hasan, M. M. F., Jayaraman, G., Karimi, I. A., \& Alfadala, H. E. (2010). Synthesis of Heat Exchanger Networks with Nonisothermal Phase Changes. Aiche Journal, 56(4), 930-945. doi:10.1002/aic.12031

Henao, C. A., \& Maravelias, C. T. (2011). Surrogate-Based Superstructure Optimization Framework. Aiche Journal, 57(5), 1216-1232. doi:10.1002/aic.12341

Humbird, D., Davis, R., Tao, L., Kinchin, C., Hsu, D., Aden, A., ... Worley, M. (2011). Process design and economics for biochemical conversion of lignocellulosic biomass to ethanol: dilute-acid pretreatment and enzymatic hydrolysis of corn stover.

Iyer, R. R., \& Grossmann, I. E. (1998). Synthesis and operational planning of utility systems for multiperiod operation. Computers \& Chemical Engineering, 22(7-8), 979-993. doi:Doi 10.1016/S0098-1354(97)00270-6

Kazi, F. K., Fortman, J. A., Anex, R. P., Hsu, D. D., Aden, A., Dutta, A., \& Kothandaraman, G. (2010). Techno-economic comparison of process technologies for biochemical ethanol production from corn stover. Fuel, 89, S20-S28. doi:10.1016/j.fuel.2010.01.001

Kim, J., Sen, S. M., \& Maravelias, C. T. (2013). An optimization-based assessment framework for biomass-to-fuel conversion strategies. Energy \& Environmental Science, 6(4), 1093-1104. doi:Doi 10.1039/C3ee24243a

Kocis, G. R., \& Grossmann, I. E. (1989). A Modeling and Decomposition Strategy for the Minlp Optimization of Process Flowsheets. Computers \& Chemical Engineering, 13(7), 797-819. doi:Doi 10.1016/0098-1354(89)85053-7

Kokossis, A. C., \& Floudas, C. A. (1994). Optimization of Complex Reactor Networks .2. Nonisothermal Operation. Chemical Engineering Science, 49(7), 1037-1051. doi:Doi 10.1016/0009-2509(94)80010-3

Kraemer, K., Harwardt, A., Skiborowski, M., Mitra, S., \& Marquardt, W. (2011). Shortcut-based design of multicomponent heteroazeotropic distillation. Chemical Engineering Research \& Design, 89(8a), 1168-1189. doi:10.1016/j.cherd.2011.02.026

Lakshmanan, A., \& Biegler, L. T. (1996). Synthesis of optimal chemical reactor networks. Industrial \& Engineering Chemistry Research, 35(4), 1344-1353. doi:DOI 10.1021/ie950344b

Lau, M. W., \& Dale, B. E. (2009). Cellulosic ethanol production from AFEX-treated corn stover using Saccharomyces cerevisiae 424A(LNH-ST). Proceedings of the National Academy of Sciences of the United States of America, 106(5), 1368-1373. doi:10.1073/pnas.0812364106

Luterbacher, J. S., Rand, J. M., Alonso, D. M., Han, J., Youngquist, J. T., Maravelias, C. T., . . Dumesic, J. A. (2014). Nonenzymatic Sugar Production from Biomass Using Biomass-Derived gammaValerolactone. Science, 343(6168), 277-280. doi:10.1126/science.1246748

Mavromatis, S. P., \& Kokossis, A. C. (1998). Conceptual optimisation of utility networks for operational variations - II. Network development and optimisation. Chemical Engineering Science, 53(8), 1609-1630. doi:Doi 10.1016/S0009-2509(97)00432-6 
Merchan, A. F., Velez, S., \& Maravelias, C. T. (2013). Tightening methods for continuous-time mixedinteger programming models for chemical production scheduling. Aiche Journal, 59(12), 4461-4467. doi:10.1002/aic.14249

Misener, R., \& Floudas, C. A. (2014). ANTIGONE: Algorithms for coNTinuous/Integer Global Optimization of Nonlinear Equations. Journal of Global Optimization, 59(2-3), 503-526. doi:10.1007/s10898-014-0166-2

Naik, S. N., Goud, V. V., Rout, P. K., \& Dalai, A. K. (2010). Production of first and second generation biofuels: A comprehensive review. Renewable \& Sustainable Energy Reviews, 14(2), 578-597. doi:10.1016/j.rser.2009.10.003

Novak, Z., Kravanja, Z., \& Grossmann, I. E. (1996). Simultaneous synthesis of distillation sequences in overall process schemes using an improved MINLP approach. Computers \& Chemical Engineering, 20(12), 1425-1440. doi:Doi 10.1016/0098-1354(95)00240-5

Papoulias, S. A., \& Grossmann, I. E. (1983a). A Structural Optimization Approach in Process Synthesis .2. Heat-Recovery Networks. Computers \& Chemical Engineering, 7(6), 707-721. doi:Doi 10.1016/0098-1354(83)85023-6

Papoulias, S. A., \& Grossmann, I. E. (1983b). A Structural Optimization Approach in Process Synthesis .3. Total Processing Systems. Computers \& Chemical Engineering, 7(6), 723-734. doi:Doi 10.1016/0098-1354(83)85024-8

Ponce-Ortega, J. M., Jimenez-Gutierrez, A., \& Grossmann, I. E. (2008). Optimal synthesis of heat exchanger networks involving isothermal process streams. Computers \& Chemical Engineering, 32(8), 1918-1942. doi:10.1016/j.compchemeng.2007.10.007

Redlich, O., \& Kwong, J. N. S. (1949). On the Thermodynamics of Solutions. V. An Equation of State. Fugacities of Gaseous Solutions. Chemical Reviews, 44(1), 233-244. doi:10.1021/cr60137a013

Rodriguez-Toral, M. A., Morton, W., \& Mitchell, D. R. (2001). The use of new SQP methods for the optimization of utility systems. Computers \& Chemical Engineering, 25(2-3), 287-300. doi:Doi 10.1016/S0098-1354(00)00654-2

Sahinidis, N. V. (2014). BARON 14.4.0: Global Optimization of Mixed-Integer Nonlinear Programs, User's manual. Retrieved from http://www.minlp.com/downloads/docs/baron\%20manual.pdf

Schweiger, C. A., \& Floudas, C. A. (1999). Optimization framework for the synthesis of chemical reactor networks. Industrial \& Engineering Chemistry Research, 38(3), 744-766. doi:DOI 10.1021/ie980460p

Sen, S. M., Henao, C. A., Braden, D. J., Dumesic, J. A., \& Maravelias, C. T. (2012). Catalytic conversion of lignocellulosic biomass to fuels: Process development and technoeconomic evaluation. Chemical Engineering Science, 67(1), 57-67. doi:10.1016/j.ces.2011.07.022

Shao, T., Krishnamurty, S., \& Wilmes, G. C. (2007). Preference-based surrogate Modeling in engineering design. Aiaa Journal, 45(11), 2688-2701. doi:10.2514/1.27777

Siirola, J. J. (1995). An industrial perspective on process synthesis. Fourth International Conference on Foundations of Computer-Aided Process Design, 222-233. Retrieved from <Go to ISI>://WOS:A1995BE08Z00025

Sinnott, R. K. (2009). Chemical engineering design: SI Edition: Elsevier.

Tawarmalani, M., \& Sahinidis, N. (2011). Convexification and Global Optimization in Continuous and Mixed-Integer Nonlinear Programming: Theory, Algorithms, Software, and Applications: Springer US.

Tawarmalani, M., \& Sahinidis, N. V. (2005). A polyhedral branch-and-cut approach to global optimization. Mathematical Programming, 103(2), 225-249. doi:10.1007/s10107-0050581-8

Trespalacios, F., \& Grossmann, I. E. (2014). Review of mixed-integer nonlinear and generalized disjunctive programming applications in Process Systems Engineering. 
Varbanov, P. S., Doyle, S., \& Smith, R. (2004). Modelling and optimization of utility systems. Chemical Engineering Research \& Design, 82(A5), 561-578. doi:Doi 10.1205/026387604323142603

Velez, S., Sundaramoorthy, A., \& Maravelias, C. T. (2013). Valid Inequalities Based on Demand Propagation for Chemical Production Scheduling MIP Models. Aiche Journal, 59(3), 872-887. doi:10.1002/aic.14021

Wilkendorf, F., Espuna, A., \& Puigjaner, L. (1998). Minimization of the annual cost for complete utility systems. Chemical Engineering Research \& Design, 76(A3), 239-245. doi:Doi 10.1205/026387698524866

Won, K. S., \& Ray, T. (2005). A framework for design optimization using surrogates. Engineering Optimization, 37(7), 685-703. doi:10.1080/03052150500211911

Yee, T. F., \& Grossmann, I. E. (1990). Simultaneous-Optimization Models for Heat Integration .2. Heat-Exchanger Network Synthesis. Computers \& Chemical Engineering, 14(10), 1165-1184. doi:Doi 10.1016/0098-1354(90)85010-8

Yeomans, H., \& Grossmann, I. E. (1999). A systematic modeling framework of superstructure optimization in process synthesis. Computers \& Chemical Engineering, 23(6), 709-731. doi:Doi 10.1016/S0098-1354(99)00003-4

Yeomans, H., \& Grossmann, I. E. (2000). Disjunctive programming models for the optimal design of distillation columns and separation sequences. Industrial \& Engineering Chemistry Research, 39(6), 1637-1648. doi:10.1021/ie9906520

Zorn, K., \& Sahinidis, N. V. (2014). Global optimization of general nonconvex problems with intermediate polynomial substructures. J. of Global Optimization, 59(2-3), 673-693. doi:10.1007/s10898-014-0190-2 